\title{
Longhouses, biografía de la casa y complejidad social en el noroeste peninsular en la alta edad media
}

\section{Longhouses, house biography and social complexity in Early Medieval North- western Iberia}

\author{
Juan Antonio Quirós Castillo ${ }^{1}$ \\ Universidad del País Vasco / Euskal Herriko Unibertsitatea
}

\begin{abstract}
RESUMEN
El objetivo de este trabajo es analizar un grupo de construcciones domésticas de cronología altomedieval de notables dimensiones que ha sido identificado e $n$ el último d ecenio e $n$ a lgunos s ectores d el n oroeste d e la península ibérica y que han sido definidas como longhouses. Este es un término que ha sido utilizado de forma implícita por parte de varias tradiciones arqueológicas para designar estructuras alargadas que cuentan con dimensiones, funcionalidades y significados sociales muy heterogéneos entre sí. Algunas tradiciones europeas han definido este tipo de estructuras en términos funcionales (casa-establo), formales ( plantas a largadas) o tipológicos, mientras que en el centro de Italia se han identificado con residencias de las élites intermedias. Tomando como caso de estudio la llanada de Álava, en este artículo se realiza una caracterización social de los contextos en los que se han hallado este tipo de construcciones y, a continuación, se analiza desde la perspectiva de la biografía cultural de la casa la articulación de las comunidades políticas locales y supralocales de este territorio.
\end{abstract}

Palabras clave: arquitectura doméstica; alta edad media; complejidad social; península ibérica; prehistoria reciente; biografía de la casa.

\begin{abstract}
The aim of this paper is to analyze large-sized domestic architectures dated in the early medieval period attested in some areas of North-western Iberia, defined as Ionghouses. This term has been used implicitly by different archaeological traditions to designate elongated structures that have very heterogeneous dimensions, functionalities and social meanings. Some European traditions have defined this type of structures in functional (byre-houses), formal (elongated plants) or typological terms, while in central Italy early medieval longhouses are considered as residence of intermediate elites. The Alava Plain case study is discussed in order to analyze the social context of longhouses occupations. Hereafter, these buildings are analyzed in the context of the house biography approach, arguing these households had a seminal role in the articulation of local and supralocal political communities.
\end{abstract}

Key words: domestic architecture; Early Medieval Period; socio-political complexity; Iberia; Late Prehistory; house biography.

Recibido: 09-06-2017. Aceptado: 15-09-2017. Publicado online: 12-12-2017

Cómo citar este artículo / Citation

Quirós Castillo, J. A. 2017: "Longhouses, biografía de la casa y complejidad social en el noroeste peninsular en la alta edad media", Arqueología de la Arquitectura, 14: e060, doi: http://dx.doi.org/10.3989/arq.arqt.2017.019

\section{Copyright}

(C) 2017 CSIC. Este es un artículo de acceso abierto distribuido bajo los términos de una licencia de uso y distribución Creative Commons Attribution (CC-by) España 3.0. 


\section{INTRODUCCIÓN}

La arqueología de la arquitectura del sur de Europa de los últimos decenios ha sido, prevalentemente, una arqueología de arquitecturas de carácter monumental tales como iglesias, templos, monasterios, fortificaciones o estructuras de relieve, cuyo estudio ha permitido renovar profundamente nuestro conocimiento de las sociedades clásicas y postclásicas desde una amplia diversidad de perspectivas (p. e. Brogiolo y Chavarria 2005; Brogiolo y Cagnana 2012; Caballero Zoreda 2013). Sin embargo, en los últimos años se ha producido un notable incremento de los trabajos dedicados al estudio de la arquitectura doméstica, de forma que en el 'IV Congresso Nazionale di Archeologia Medievale Italiana' celebrado en San Galgano en el año 2006 se propuso acuñar el término 'Archeologia delle architetture' con el fin de reivindicar una apertura conceptual y temática hacia este universo construido (Francovich y Valenti 2006). El hecho de que esta sugerencia terminológica no haya sido acogida de forma unánime es un síntoma de que esta dicotomía ha sido rápidamente superada, de tal forma que tanto en España como en Italia se han ido publicando en los últimos años varios estudios monográficos y trabajos colectivos de carácter arqueológico que han puesto en el centro del análisis social el estudio de las arquitecturas domésticas. ${ }^{2}$

Por otro lado, la arqueología de las arquitecturas domésticas constituye, sin duda alguna, el vector más dinámico de la arqueología de la arquitectura en ámbito anglosajón, tal y como muestra el reciente manual de S. R. Steadman (2015). El desarrollo desde los años 70 de líneas de investigación que se reconocen en experiencias como la settlement archaeology, la household archaeology, la sintaxis espacial, las sociedad-casa de Levi Strauss y, más recientemente, los estudios que exploran la dimensión simbólica e ideológica del espacio doméstico, han dado pie a una producción abundante e informada en términos teóricos de particular interés (p. e. Joyce y Gillespie 2000; Cutting 2006; Beck 2007; Moore 2012). Y aunque muchas de estas reflexiones teóricas no hayan tenido más que un reflejo puntual en la arqueología de la arquitectura doméstica europea, a fecha de hoy éste es un campo transversal muy dinámico en el que sería posible establecer formas de mestizaje intelectual entre distintas tradiciones arqueológicas.

\footnotetext{
La bibliografía es muy abundante, pero se pueden señalar entre otros trabajos los de Galetti 2010; Santangeli Valenzani 2011; Gutiérrez y Grau 2013; Díez Jorge y Navarro Palazón 2015; así como el monográfico publicado en el volumen 9 de esta misma revista (Quirós Castillo 2012b).
}

Uno de los ámbitos que más se ha visto beneficiado por el impulso del estudio de las estructuras domésticas ha sido, sin duda alguna, el análisis de las sociedades europeas altomedievales. El desarrollo de una arqueología de las arquitecturas domésticas altomedievales en el suroeste de Europa, y en particular el estudio de las arquitecturas realizadas en materiales efímeros, ha contribuido de forma decisiva a superar la identificación entre arquitecturas de madera y sociedades simples, pobres e itinerantes, planteando propuestas interpretativas mucho más articuladas ( $\mathrm{p}$. e. Vigil-Escalera 2007; Fronza 2011; Santangeli Valenzani 2011; Azkarate y Solaun 2015). Pero mientras que en países como Inglaterra, Italia, Francia o en el centro de Europa se han llevado a cabo estudios que han inventariado y analizado de forma sistemática este tipo de arquitecturas (Rahtz 1976; Donat 1980; Peytremann 2003; Fronza 2005), los registros de la península ibérica no cuentan aún con un tratamiento integral y sistemático. Son varias las razones que pueden explicar esta carencia.

En primer lugar, el hecho de que la mayor parte de las intervenciones arqueológicas realizadas en los últimos veinte años que han proporcionado arquitecturas domésticas altomedievales en España y en Portugal han sido realizadas en el marco de proyectos preventivos o de urgencia en los que la administración ha delegado en los profesionales y las empresas de arqueología los criterios de actuación, documentación y análisis. Como consecuencia de ello, y en función de las distintas praxis que se han generado en cada territorio, se han obtenido resultados muy variados en cada comunidad autónoma, en cada provincia o incluso en cada proyecto. Esta ausencia de coordinación se ha traducido en que, a fecha de hoy, no solamente no haya un catálogo centralizado de la arqueología preventiva realizada en España en los últimos veinte años comparables a los elaborados en otros países europeos, sino que ni siquiera sea posible saber el número de yacimientos que han sido intervenidos. Si a ello sumamos la escasa implicación de los centros de investigación, el hecho de que muchas empresas hayan desaparecido, y que muchos arqueólogos hayan dejado la profesión en el contexto de la crisis actual quedando informes y memorias por elaborar, solo podemos concluir que muchas excavaciones arqueológicas preventivas y de urgencia ejecutadas, nunca han tenido lugar.

En segundo lugar, aunque algunos grupos de investigación peninsulares y profesionales han potenciado 
notablemente el estudio de las arquitecturas domésticas altomedievales en los últimos años, el número de casos de estudio analizados y publicados es aún limitado (p. e. Vigil-Escalera 2000; Roig 2009; Quirós Castillo 2011; Gutiérrez Lloret 2012; Azkarate y Solaun 2015; Tejerizo 2012, 2013 y 2017), lo que dificulta notablemente la comparación territorial y contextual. Esta carencia se hace aún más patente en el noroeste de la península ibérica, que apenas cuenta con un puñado de monografías publicadas con un cierto grado de detalle de contextos domésticos altomedievales. ${ }^{3} \mathrm{Y}$ aunque nos consta que hay ejemplos aún inéditos, no se ha logrado aún consolidar-salvo excepciones puntuales- una línea de investigación específica en torno a esta temática comparable a la de otros países europeos.

En tercer lugar, la ausencia de una tradición de estudios local, en particular en lo que se refiere a las arquitecturas realizadas en materiales efímeros, puede haber determinado una excesiva dependencia tanto terminológica como conceptual respecto a otras tradiciones europeas en el análisis de estas evidencias materiales. La literatura hispana recurre con frecuencia a conceptos tomados de otros idiomas (p. e. fondo de cabaña, longhouse, clayonnage, façonnage direct, etc.), sin que todos estos términos hayan sido adecuadamente discutidos. En trabajos previos se ha realizado un esfuerzo a la hora de conceptualizar categorías como 'fondo de cabaña' o estructuras de fondo rehundido (Azkarate y Quirós Castillo 2001; Tejerizo 2015) diferenciándolas respecto a las estructuras aéreas, pero hay otros conceptos que se utilizan de forma implícita. En otras ocasiones se asume por contagio que los 'fondos de cabaña' han de ser estructuras auxiliares, o que las inferencias funcionales, morfológicas, simbólicas, sociales o políticas realizadas en el espacio carolingio o anglosajón pueden ser utilizadas directamente para dar sentido a las evidencias materiales hispanas. Desde nuestro punto de vista resultaría más provechoso recurrir a un enfoque diacrónico regional antes que sincrónico continental, aunque en ocasiones sea casi inevitable recurrir a trabajos realizados en otros sectores europeos.

El objetivo de este trabajo será el estudio de una serie de construcciones singulares de notables dimensiones realizadas con materiales efímeros halladas en los

\footnotetext{
3 Entre los principales trabajos realizados en el noroeste hay que señalar los de Peñaferruz (Gutiérrez González 2003), las aldeas madrileñas y de la cuenca del Duero (Vigil-Escalera 2007; Quirós Castillo 2013b; Tejerizo 2017), El Pelambre (González Fernández 2009), Zaballa (Quirós Castillo 2012a), Gasteiz (Azkarate y Solaun 2013) o Zornoztegi (Quirós Castillo e. p.).
}

últimos años en varios sectores del noroeste peninsular que han sido definidas como longhouses. Tal y como veremos, este término ha sido utilizado para caracterizar tanto construcciones de la prehistoria reciente como de la alta edad media. Pero más allá del interés clasificatorio o tipológico, el análisis de estas arquitecturas es relevante porque en diversos trabajos realizados en el centro de Italia, se ha considerado que las longhouses identifican residencias de élites rurales menores altomedievales ${ }^{4} \mathrm{de}$ tal manera que, en lugares como Poggibonsi (Siena), una estructura de este tipo constituye el eje de un centro dominical carolingio (Valenti 2004; Francovich y Valenti 2007). Esta interpretación ha sido posteriormente extendida también al ejemplo de Gasteiz, donde se ha hallado una longhouse que ha sido identificada con una ocupación de estatus social privilegiado (Azkarate y Solaun 2012: 128) ¿Pero son realmente residencias de élites todas las longhouses del suroeste de Europa? ¿Se puede emplear esta categoría también en la península ibérica? ¿Por qué se localizan solamente en algunas zonas? ¿En qué contextos sociopolíticos aparecen?

El análisis de una tipología arquitectónica específica es un ejercicio altamente arriesgado porque, por un lado, se puede caer en el error de la cosificación del objeto de estudio abrazando planteamientos formalistas, culturalistas o funcionalistas. Más allá de su dimensión material, la "casa" debe ser considerada, en primer lugar, como una entidad social en sí misma, y por lo tanto es una escala de análisis de procesos sociales (Beck 2007). ${ }^{5}$ Pero además, la arquitectura doméstica no es un mero reflejo pasivo de prácticas sociales o un marcador que identifique un cierto tipo de clase, grupo o élite, sino que es un instrumento activo de construcción de identidades, hábitos sociales y comunidades políticas (Gerritsen 2008; Blanco González 2011; Steadman 2015). Por otro lado, si hay un criterio que define la arquitectura doméstica es el de su permanente transformación en función de las dinámicas de los sujetos sociales residentes, lo que va en contra del análisis estático y tipológico de las formas arquitectónicas 'tradicionales'. Los estudios realizados sobre la temporalidad de los espacios domésticos en términos de

\footnotetext{
4 Sobre el concepto de élites en la Alta Edad Media véase Wickham 2011; sobre el concepto de 'élites rurales menores' véase Nissen Jaubert 2010: 256. Otros autores han recurrido a categorías como 'middling elites' (Loveluck 2013: 124), 'élites intermedie' (Collavini 2007) o 'middle range people' (Davies 2016: IX) para referirse a un denso y fluido espacio de movilidad social del que forman parte sujetos que raramente aparecen en la documentación textual y que actúan a escala local y, sobre todo, supralocal.

5 Sobre los distintos enfoques teóricos de análisis de la "casa", tanto en términos sociales como materiales, véase Gillespie 2007.
} 
cambios y permanencias espaciales (procesos de desplazamiento, reconstrucción y perduración de las estructuras domésticas) en la prehistoria reciente son particularmente iluminantes desde esta perspectiva (Brück 2000; Gerritsen 2007). Por último, tanto las longhouses como otras estructuras asociadas no se presentan aisladas, sino que forman parte de espacios domésticos articulados y cambiantes, por lo que la escala de análisis de referencia es la parcela doméstica (Vigil-Escalera 2015: 522-526). Sin embargo, el estado de conservación de los espacios domésticos altomedievales no siempre permite recurrir con una cierta solidez a esta escala de análisis, por lo que suele ser común que sean construcciones como la longhouse las que se conviertan en el foco de atención (p. e. Moreno 2014).

Asumiendo estos riesgos, y dejando para futuros trabajos el análisis detallado de otras escalas analíticas (parcelas domésticas, comunidades, sistemas territoriales), en esta ocasión se priorizará el estudio de las denominadas longhouses debido a las connotaciones sociopolíticas que han adquirido en los relatos sobre la conformación y articulación de los centros de poder local en el sur de Europa. En primer lugar, se realizará un acercamiento al concepto mismo de longhouse, tal y como ha sido empleado por parte de la arqueología hispana y europea. A continuación, se realizará una caracterización social de los contextos en los que han aparecido longhouses de cronología altomedieval en un caso de estudio, el de la llanada alavesa. Por último, y siguiendo el marco teórico de la biografía cultural de las casas, se explorará el proceso de construcción de las comunidades políticas locales a través del estudio de la arquitectura doméstica a partir de la comparación de la arquitectura doméstica de la llanada alavesa.

\section{¿CÓMO DEFINIR UNA LONGHOUSE?}

Hay algunas construcciones domésticas que son más fáciles de identificar, definir e interpretar que otras. Las estructuras negativas son, normalmente, las primeras en ser identificadas. No es, por lo tanto, extraño, que hayan sido los 'campos de hoyos' o 'campos de silos' las primeras categorías empleadas por los especialistas para definir, en el noroeste peninsular, los espacios domésticos de la prehistoria reciente y la alta edad media ( $\mathrm{p}$. e. Caballero 1989: 123-124; González González 1994), seguidas a continuación por los 'fondos de cabaña' o estructuras de fondo rehundido (Tejerizo 2015). Solamente la realización desde los años 90 de excavaciones en extensión ha permitido reconocer con claridad estructuras domésticas realizadas sobre postes o sobre zócalos, entre las que se encuentran las estructuras denominadas como longhouse.

En rigor, el término longhouse es una categoría de clasificación y análisis de arquitecturas domésticas empleada de forma más o menos implícita por parte de numerosas tradiciones arqueológicas en todo el mundo designando realidades materiales, funciones, dimensiones y sociales muy heterogéneas. Mientras que en el sureste de Asia una única longhouse está diseñada para acoger una comunidad completa (las denominadas longhouse villages), las longhouses de los iroqueses o 'gentes de las casas largas' de Norteamérica son estructuras residenciales multifamiliares que acogen la familia matrilineal extensa; en el Algarve portugués se han documentado algunas construcciones alargadas de grandes dimensiones empleadas como habitaciones de pescadores; en cambio las longhouses vikingas acomunan funciones como la residencial, la exhibición social o la realización de rituales y actos sociales que incluyen banquetes colectivos (Veiga de Oliveira et al. 1994: 239-240; Metcalf 2010; Moore 2012). Aunque la casuística podría ampliarse ulteriormente (véase p. e. Guidoni 1989: 106-191; Steadman 2015: 115-118, 242, 275-276 y 281-283), resulta evidente que el concepto de longhouse es extremadamente vago y adquiere significados muy diferentes en cada contexto.

Quizás simplificando en exceso, en la literatura especializada europea se pueden diferenciar al menos tres formas de utilizar esta categoría, no necesariamente excluyentes entre sí, para referirse a arquitecturas fechadas desde la prehistoria reciente hasta la época moderna.

El término longhouse fue acuñado como tal en el Reino Unido en los años 20 por I. C. Peate a partir de la traducción literal de un vocablo presente en la documentación medieval galesa para definir una casa que contaba en uno de sus extremos con un espacio dedicado al ganado (Hurst 1971; Alcock y Smith 1972). En el centro de Europa y en el área escandinava, donde se funden las trayectorias de la arqueología de la prehistoria reciente y de la alta edad media, ésta es la noción de longhouse predominante: se trata de una estructura caracterizada por la coexistencia bajo un mismo techo de animales y personas (Hurst 1971: 104-107; Klápště y Nissen Jaubert 2007: 89-92). Así por ejemplo, en su glosario sobre arquitectura de madera, L. Volmer y H. Zimmermann definen la longhouse o langhaus como: 
...elongated building of usually one storey and without aisles. It combines dwelling and barn; in the simplest form man and beast cohabit at opposite ends of a single room; at most, a partition separates the lower-end byre from the upper-end living space. The entrances are situated approximately in the middle of both side walls and in this way a cross passage divides the functional units (Volmer y Zimmermann 2012: 92-94).

En otra entrada del mismo volumen ambos autores asocian o identifican el concepto de longhouse con el de byre-house (Volmer y Zimmermann 2012: 48-49), aunque mantienen las dos entradas separadas. También en Escandinavia se establece una relación estrecha entre forma y función, de tal forma que K. Anstrong Oma ha señalado recientemente que, aunque no todas las longhouses hayan acogido siempre y necesariamente animales, la creación de este tipo constructivo - que estuvo vigente durante 2500 años en este territorio (desde la Edad del Bronce hasta el final del período vikingo)-, fue el resultado del establecimiento de una nueva relación entre las personas y los animales (en particular el ganado vacuno), así como del desarrollo de determinadas prácticas sociales a escala local (Amstrong Oma 2016). Pero frente a esta visión estática de larga duración $\mathrm{H}$. Hamerow ha mostrado que, en distintos sectores del noroeste europeo, la clásica longhouse compartimentada con establo fue sustituida en el siglo VIII por una construcción abierta, sin divisiones internas y sin establo, de manera que el módulo unicelular compartimentado - que a su vez contaba con otros edificios auxiliares- fue reemplazado por una serie de construcciones funcionalmente especializadas (Hamerow 2002: 14-26). En cambio, en Francia no se ha recurrido al concepto de longhouse para analizar la arquitectura doméstica altomedieval (p. e. Peytremann 2003: 280-292), pero sí se han estudiado algunas maison-étable estrechamente vinculadas con las longhouses del noroeste continental (Nissen Jaubert 2003).

En contraposición a esta definición prevalentemente funcional, considerada por muchos como la única definición posible (p. e. Fokkens 2003; Klápště y Nissen Jaubert 2007; Gerritsen 2008), otros investigadores han definido la longhouse en términos estrictamente formales y/o dimensionales, como un tipo arquitectónico alargado carente de una caracterización funcional específica (p. e. Meiron-Jones 1973; Fronza 2005: 281 y 359; Azkarate y Solaun 2013: 332). Esta es, sin duda alguna, la forma de empleo más extendida de esta categoría arquitectónica fuera de Europa y al sur del Rin, incluyendo España y en general el suroeste de Europa ${ }^{6}$ (Klápště y Nissen Jaubert 2007: 92). Y es desde esta perspectiva que la residencia señorial del centro dominical de Poggibonsi (Siena) ha sido definida como una longhouse, con el fin de remarcar las diferencias dimensionales y morfológicas respecto al resto de las viviendas y las construcciones auxiliares del poblado (Valenti 2004; Fronza 2005: 141-203). En el Reino Unido - donde hay un claro consenso a la hora de negar la existencia de longhouses altomedievales similares a las continentales (es decir, a las byre-houses), puesto que solamente se documentan a partir del siglo XIII (Gardiner 2014)- se utiliza el término hall para denominar las grandes construcciones (normalmente alargadas) de carácter comunitario y de representación que aparecen en algunas localidades (Hamerow 2012: 46-48; Pollington 2012; Brenna y Hamerow 2015). Pero en términos conceptuales no se considera que una hall sea una longhouse o un tipo de ellas, aunque ambas sean construcciones alargadas (Loveluck 2013: 253; Gardiner 2016).

Una tercera y última caracterización es aquélla que define la longhouse, o mejor, tipos concretos de longhouses, como "tipos arquitectónicos" bien definidos y estandarizados. Este es por ejemplo el caso del denominado tipo Warendorf (Chapelot y Fossier 1980: 79-88) que identifica construcciones alargadas realizadas con los lados largos curvos 'a forma de barca' durante los siglos VII-VIII y que fue reconocido por vez primera en los años 50 en el yacimiento homónimo de Westfalia. Más allá de su valencia cronotipológica, los procesos de estandarización de la arquitectura doméstica precisarían de análisis tanto socioeconómicos (Gelichi y Librenti 1997) como simbólicos e ideológicos (Cutting 2006: 230-231) que explorasen las implicaciones de la aparente difusión de determinadas prácticas sociales.

\footnotetext{
En España se han descrito en los últimos años varias longhouses fechadas entre el Bronce Final y el Hierro I (Moreno 2014). Hasta la fecha los principales hallazgos se localizan en Galicia (Vázquez Liz et al. 2015), en la cuenca del Duero (Misiego et al. 2005, Villanueva et al. 2014), en la cuenca del Tajo (Sanguino et al. 2007; Urbina et al. 2007; Agustí et al. 2012; Urbina y Urquijo 2012; Flores y Sanabria 2012) y en Navarra (Unanua y Erce 2014). En la mayor parte de estos trabajos el concepto de longhouse ha sido empleado para describir construcciones alargadas (proporciones entre 1:2 a 1:4) de planta rectangular u ovalada realizadas sobre postes, con extremos rectos o curvos, aunque también hay algún ejemplo de construcciones definidas mediante rebajes o rozas perimetrales que han sido asimiladas a este tipo arquitectónico (p. e. Vázquez Liz et al. 2015: 15). Por lo que se refiere a su funcionalidad, la mayoría de los especialistas sugieren que las longhouses han tenido una función residencial (Sanguino et al. 2007; Urbina et al. 2007; Agustí et al. 2012: 127), comunitaria (Flores y Sanabria 2012; Unanua y Erce 2014) y, en algún caso, ceremonial (Vázquez et al. 2015), sin que se haya entrado a considerar la presencia o no de espacios de estabulación interna.
} 
En definitiva, en este sintético recorrido se puede observar que el término longhouse se utiliza para designar realidades materiales diferentes en función de las distintas tradiciones de estudio, y por lo tanto esta categoría debe ser analizada en contextos cronológicos y culturales concretos. Desde un punto de vista estrictamente geográfico la "gran familia de las longhouses" (Fronza 2011: 97) se distribuye principalmente por el centro y el norte de Europa, mientras que su presencia es mucho más reducida en las periferias, y en particular en el suroeste de Europa, aunque el número de hallazgos ha ido aumentando en los últimos años. Así por ejemplo, en Italia se han identificado como tales al menos 17 longhouses altomedievales en nueve yacimientos (Fronza 2005: 760; Vaccaro 2005: 293; Bianchi 2012; Bianchin et al. 2012), pero es probable que su número sea aún mayor. En Italia, pero también en la península ibérica, es la segunda acepción la que se ha afirmado, por lo que será preciso definir, en términos contextuales, los significados sociales e ideológicos de estas construcciones.

\section{LAS LONGHOUSES EN EL NOROESTE PENINSULAR EN LA ALTA EDAD MEDIA: EL CASO DE LA LLANADA ALAVESA}

A pesar de que ha sido sugerida la existencia de longhouses en el interior peninsular ya desde el período visigodo (Arce 2011: 41) o en centros altomedievales como es el caso de la ciudad de Oviedo (Estrada García 2014: 200), la realidad es que el catálogo de yacimientos altomedievales en los que se ha reconocido este tipo de estructuras es aún incluso más reducido que el de la prehistoria reciente (Tejerizo 2013: 323). Es cierto que también en esta ocasión nos consta que hay ejemplos inéditos de construcciones domésticas alargadas o no reconocidos adecuadamente que, quizás, se den a conocer en el futuro (Fig. 1).

Por otro lado, el avance de los estudios sobre la arquitectura doméstica altomedieval en la península ibérica ha mostrado la existencia de una notable regionalización en lo que se refiere a las técnicas, morfologías y organización social de los espacios domésticos altomedievales, de tal forma que, por ejemplo, las arquitecturas sobre postes portantes de madera parecen estar prácticamente ausentes en el área mediterránea o en amplios sectores del interior, mientras que son mucho más frecuentes en el cuadrante noroccidental (p. e. Roig
2009; Quirós Castillo 2011; Gutiérrez Lloret 2012). Asimismo, en el valle del Duero se ha reconocido la existencia de importantes diferencias constructivas a escala subregional en época visigoda (Tejerizo 2012).

Teniendo en cuenta todo ello centraremos nuestra atención en esta ocasión únicamente en una subregión, la llanada alavesa, que es uno de los territorios que cuenta con una masa crítica de datos sobre la arquitectura doméstica altomedieval más significativa, muchos de ellos ya publicados. Se trata de una subregión que tenía ya en la alta edad media una identidad sociopolítica propia, cuya primera manifestación conocida e institucionalizada es el condado de Álava, documentado en el siglo X. Al igual que toda el área castellana, Álava carece de centros urbanos en este período, y hasta el momento tampoco se conocen centros fortificados que puedan ser identificados como central places antes del siglo X. Es por ello que los ejes de articulación política eran centros rurales de distinta entidad en los que se localizan iglesias, pequeños monasterios como los de Acosta, Zaballa, Bolívar o Esquivel, o incluso sedes episcopales como la de Armentia. Pero también es en los centros rurales donde residen las élites y las aristocracias. ${ }^{7}$ En un contexto de esta naturaleza el estudio de la arquitectura doméstica adquiere un significado relevante para analizar las formas de articulación de los poderes locales en términos comparativos.

Hasta el momento son solamente dos los yacimientos de cronología altomedieval en la llanada alavesa en los que se han descrito estructuras domésticas consideradas como longhouses según los estándares definidos previamente: Gasteiz y Aistra. A continuación, se analizarán brevemente ambos yacimientos desde una perspectiva social con el fin de encuadrar el contexto en el que se realizaron estas construcciones.

El registro material de la aldea de Gasteiz (VitoriaGasteiz) es bien conocido porque ha sido objeto de varias publicaciones recientes que, con el tiempo, han ido añadiendo matices o recogiendo interpretaciones algo más sólidas y rotundas respecto a los primeros trabajos (Azkarate y Quirós Castillo 2001; Azkarate y Solaun 2012, 2013 y 2015). En el marco del proyecto de rehabilitación de la Catedral de Santa María se ha llevado a cabo por vez primera en el noroeste peninsular una intervención extensiva que ha permitido reconocer

\footnotetext{
Una caracterización sociopolítica del territorio en la Alta Edad Media se puede consultar en García de Cortázar 1997; García de Cortázar 2005; Santos Salazar y Quirós Castillo e. p.
} 


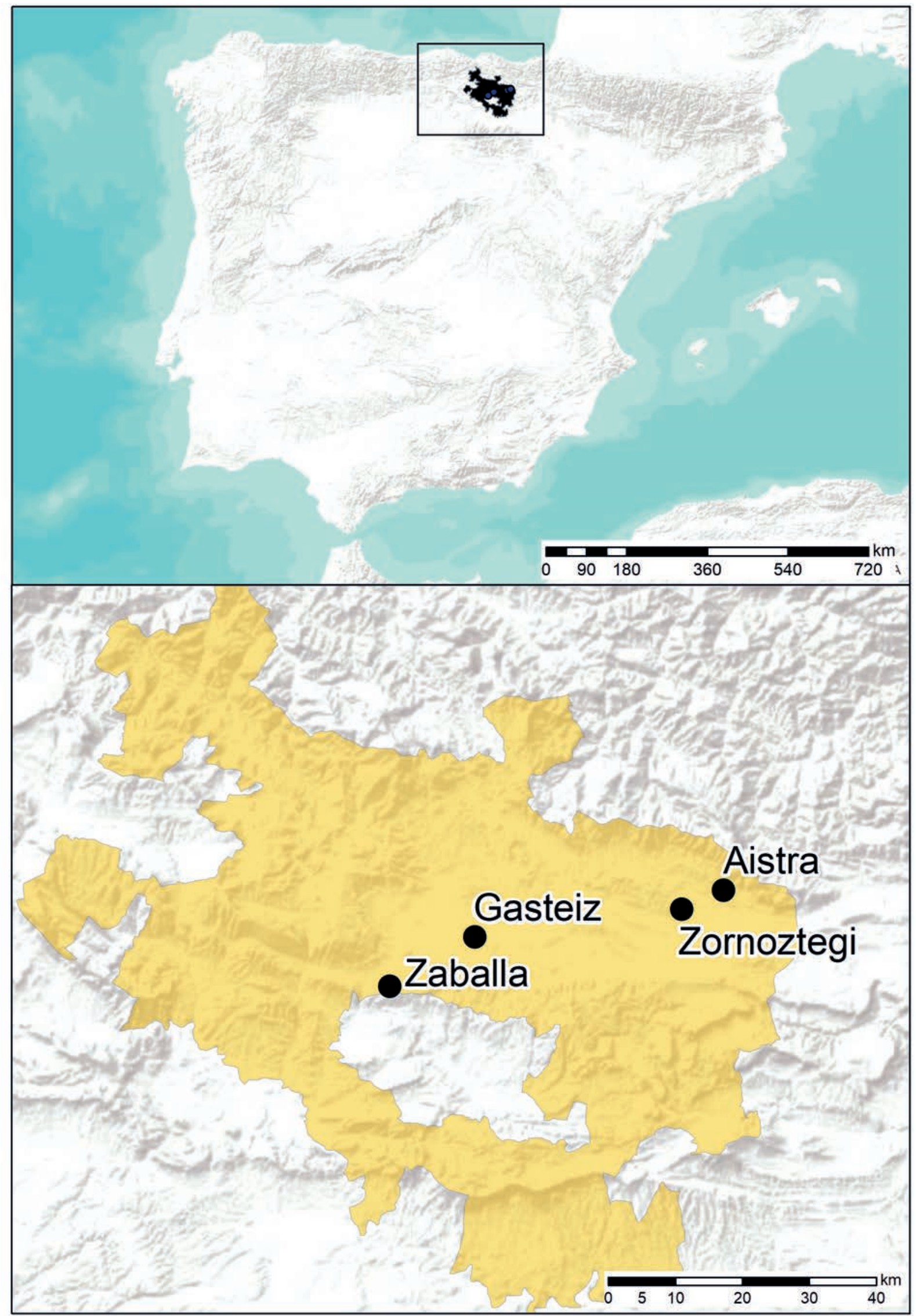

Fig. 1. Mapa con la localización de los principales yacimientos analizados en el texto. 
dos parcelas domésticas altomedievales razonablemente bien conservadas, debido precisamente a que las construcciones eclesiásticas han preservado los depósitos domésticos altomedievales.

De forma sucinta se ha descrito la organización espacial de Gasteiz durante el primer período (700-950) en términos de patrón agregado de naturaleza alveolar conformado por parcelas domésticas definidas a su vez como espacios domésticos desagregados. En este primer período las distintas estructuras y elementos constructivos se disponen en torno a un espacio abierto de manera que cada una de ellas cuenta con funciones diferenciadas incluyendo construcciones de uso residencial, cierres para el ganado, espacios y estructuras de función artesanales, áreas de almacenaje o áreas de abastecimiento, entre otros. Dentro de este primer período se han diferenciado dos fases distintas (fase 1, 700-850; fase 2, 850-950), de manera que la comparación ente las dos plantas de fase (Azkarate et al. 2013: fig 7.2 y 7.4) revela la existencia de cambios, pero también de continuidades muy significativas en lo que se refiere principalmente a la organización del espacio doméstico y la disposición de los espacios de almacenaje y residenciales. Resulta particularmente significativo observar cómo la vivienda de la segunda fase (A1) se superpone a la de la primera fase (A7). La más antigua es una estructura probablemente alargada, realizada sobre postes perimetrales e interiores, aunque no ha sido posible estimar sus dimensiones debido a su precaria conservación. La más moderna, definida como una longhouse de $18 \times 8,5 \mathrm{~m}$, es una estructura alargada definida por una treintena de postes de madera y una roza perimetral (Azkarate et al. 2013: 400 y 404). El rasgo más significativo de esta estructura es que fue reparada en varias ocasiones, de tal forma que se han hallado secuencias de postes que se cortan entre sí (Azkarate y Solaun 2012: 113). La ausencia de 'suelos' en ambas estructuras ha llevado a sugerir que contarían con tarimas de madera en suspensión. Ello determina que sea muy difícil establecer la funcionalidad de la estructura, aunque se haya apostado por una interpretación residencial teniendo en cuenta la funcionalidad posterior de este espacio y los hallazgos realizados en los depósitos de amortización (Azkarate y Solaun 2012).

La tesis principal defendida por los responsables de la excavación es que la parcela doméstica principal indagada en este yacimiento se corresponde con una ocupación de 'estatus social privilegiado' durante toda la alta edad media, hasta el punto que ha llegado a sugerirse que se trata de la residencia de los condes de
Álava, los Vela (Azkarate et al. 2013: 473). La interpretación social propuesta reposa, principalmente, sobre lo que se denomina el control del proceso de producción siderometalúrgico, el hallazgo significativo de materiales cerámicos importados, la capacidad de almacenaje estimada, la larga perduración funcional del lugar donde se ubica la estructura residencial principal, así como el carácter jerárquico en términos espaciales que ejerce la longhouse (Azkarate et al. 2013).

Sin duda la interpretación social de estos contextos domésticos es compleja (Azkarate y Solaun 2015: 542), y un análisis comparativo con otros yacimientos del noroeste permite proponer algunos matices o incluso alternativas a este cuadro tan sugerente. ${ }^{8}$ Así por ejemplo, se podría contemplar la posibilidad de que la estructura A7 ubicada bajo la longhouse A1 pudiese ser también interpretada a su vez como una longhouse previa si se utilizase el criterio clasificatorio inicial (Azkarate y Quirós Castillo 2001: 37, n. 14). Asimismo, creo que podrían contemplarse otras posibles interpretaciones de algunos elementos utilizados para definir el estatus social de los habitantes de esta parcela. Así por ejemplo, la existencia de conjuntos de silos utilizados a lo largo de uno o dos siglos es un fenómeno que se documenta con facilidad en varias unidades domésticas de familias campesinas comunes en aldeas altomedievales de Madrid o del País Vasco. Y aunque, como en el caso de Gasteiz, existe la posibilidad de que algunos de ellos estuviesen en uso a la vez siguiendo las informaciones proporcionadas por las relaciones estratigráficas, la disposición espacial o los rellenos secundarios o terciarios (p. e. en Zornoztegi la serie de silos alineados ue 4100, 4102, 4013; en Zaballa ue 3902, 3904, 3905, 3911), este extremo no es siempre fácil de demostrar de forma indiscutible. Es también posible sugerir que los grupos de silos hallados en Gasteiz, interpretados en términos de silos de renta (Azkarate y Solaun 2015: 557), fuesen estructuras destinadas al almacenaje de 'excedente normal' por parte de productores con el fin de reducir el riesgo interanual (Halstead 1989; Wintherhalder et al. 2015) y que hayan tenido un ritmo de uso y reemplazo similar al observado en otros yacimientos. ${ }^{9}$ La diversificación del registro carpológico podría ir en esta dirección, pero hay que ser conscientes de que este registro arqueobotánico es siempre difícil de historiar en términos sociales (De Hingh y Bakels 1996). En cambio,

\footnotetext{
8 No se pretende en esta ocasión hacer una valoración comparativa y sistemática de los marcadores de complejidad social en el contexto del noroeste peninsular, pero véase ahora Quirós Castillo 2016.

9 Sobre la noción de excedente en Arqueología véase ahora Bogaard 2017 y Hastorf y Foxhall 2017.
} 
hay un cierto consenso a la hora de considerar los patrones alimentarios que se infieren a partir de los registros arqueozoológicos como un marcador relevante de complejidad social (Loveluck 2013: 66-70; Sykes 2014: 149 y ss.; Grau 2017). Y los materiales de Gasteiz no muestran patrones de consumo propios de grupos aristocráticos ${ }^{10}$ según los estándares actualmente disponibles en lo que se refiere al consumo de animales salvajes, de animales jóvenes o de representación de determinadas especies (Grau 2015 y 2016).

Dicho de otra forma, no cabe duda de que hay elementos suficientes como para pensar que Gasteiz en la alta edad media fuese un centro relevante en términos sociopolíticos en el contexto de la llanada alavesa. O que en las parcelas domésticas indagadas haya claros marcadores de distinción social. ${ }^{11}$ Otra cuestión diferente es establecer con criterios materiales objetivables la escala de acción política de los habitantes de la longhou$s e$, o incluso del entero núcleo de Gasteiz antes del año 1000. Para apurar estas cuestiones creo que sería muy útil contar con análisis comparativos a escala subregional, así como construir, a partir de registros materiales, categorías de análisis social más complejas y matizadas de las que generalmente utilizamos en la Arqueología medieval (Loveluck 2013: 13-14 y 98-99).

El segundo caso de estudio analizado es el del despoblado de Aistra (Zalduondo-Araia), situado en el extremo oriental de Álava y objeto de excavación mediante un proyecto conjunto entre la University College London y la Universidad del País Vasco. ${ }^{12}$ Aistra es un asentamiento polinuclear articulado en torno a, al menos, dos ejes: un primer sector situado en el llano, donde se preserva el topónimo de Aistra y las fotografías aéreas han mostrado la existencia de anomalías de carácter arqueológico, y un segundo sector denominado San Julián, donde se ubica en la actualidad la ermita del

\footnotetext{
10 En particular, en el período 2 ( $c a$. 950-1000 d C) en el que se fecha la longhouse predominan los animales adultos sobre los jóvenes, estrategias de cría orientadas a la obtención de productos secundarios y la presencia de animales salvajes es muy reducida (Castaños 2013: 301-312 y 322).

11 Algunos de los 'marcadores' de complejidad social podrían ser analizados más en términos contextuales (conjunto de Gasteiz) que puntuales (unidad doméstica concreta), como es el caso de los materiales muebles o la existencia de espacios artesanales especializados. Se podría argüir, por ejemplo, que la principal unidad doméstica indagada fuese en realidad un espacio doméstico periférico en términos espaciales, que no necesariamente en términos sociales, si se asume que el proceso de reducción del hierro tuvo lugar aquí.

12 En la actualidad se remata una monografía sobre el yacimiento. Además de los informes anuales editados en la revista Arkeoikuska (Reynolds y Quirós Castillo 2006-2009), se han publicado distintos trabajos sobre temáticas específicas. Una breve presentación de la secuencia ocupacional se encuentra en Quirós Castillo 2011.
}

siglo X de San Julián y Santa Basilisa ${ }^{13}$ (Fig. 2). Los trabajos arqueológicos se han focalizado en este último sector, y en particular en el entorno de la ermita, aunque recientes prospecciones geofísicas extensivas han permitido definir con detalle la naturaleza de la ocupación del área de San Julián.

La excavación de una extensión de $c a .3000 \mathrm{~m}^{2}$ ha permitido reconocer una densa ocupación doméstica altomedieval, aunque su interpretación ha estado penalizada porque parte de los depósitos han sido arrasados como resultado de las prácticas agrarias que han tenido lugar una vez que el lugar se despobló. ${ }^{14}$ Aunque se ha detectado una larga secuencia ocupacional que arranca en el período romano y se prolonga hasta la plena edad media, en esta ocasión nos centraremos únicamente en dos de las fases de cronología altomedieval: una primera ocupación de naturaleza doméstica que se puede situar entre el siglo VI y todo el siglo VII, y una segunda fase de carácter doméstico y funerario fechada entre los siglos VIII y IX.

La primera ocupación está conformada por una serie de estructuras de fondo rehundido y por una longhouse que ha sido excavada de forma parcial (E6). Se trata de una construcción rectangular con un extremo semicircular de al menos $20 \times 8 \mathrm{~m}$ de longitud. En su lado oeste está delimitada por una serie de grandes agujeros de poste, y en el sur por una roza perimetral semicircular similar a la hallada en Gasteiz y en otras construcciones domésticas identificadas en Gorliz (Bizkaia). ${ }^{15}$ Es posible que esta roza estuviese destinada a acoger una pared de tierra reforzada con postes. En el interior del edificio se reconocieron una serie de agujeros de postes alineados que permite pensar que su interior estaba compartimentado en, al menos, dos ambientes separados. Sin embargo, solamente se ha identificado una única puerta en el sur, por lo que no es posible saber si los distintos ambientes contaban con accesos separados. La presencia de postes dobles y de otras reparaciones permite pensar que la construcción estuvo en uso durante un largo periodo de tiempo que ha sido estimado en unos dos siglos en función de las dataciones radiométricas realizadas. Al sur de esta estructura se han hallado algunos

\footnotetext{
13 Sobre las ocupaciones medievales polinucleares véase Taylor 1977.

14 A este propósito es relevante subrayar que la naturaleza del sustrato rocoso de la llanada alavesa, un fondo de mar cretácico plástico, determina que los procesos postdeposicionales sean muy diferentes a los de otros sectores o cuadrillas alavesas, como puede ser el caso de la Rioja Alavesa o los Valles Occidentales.

15 Sobre Gorliz véase Campos 2015. En la actualidad T. Campos prepara su tesis doctoral sobre este yacimiento.
} 


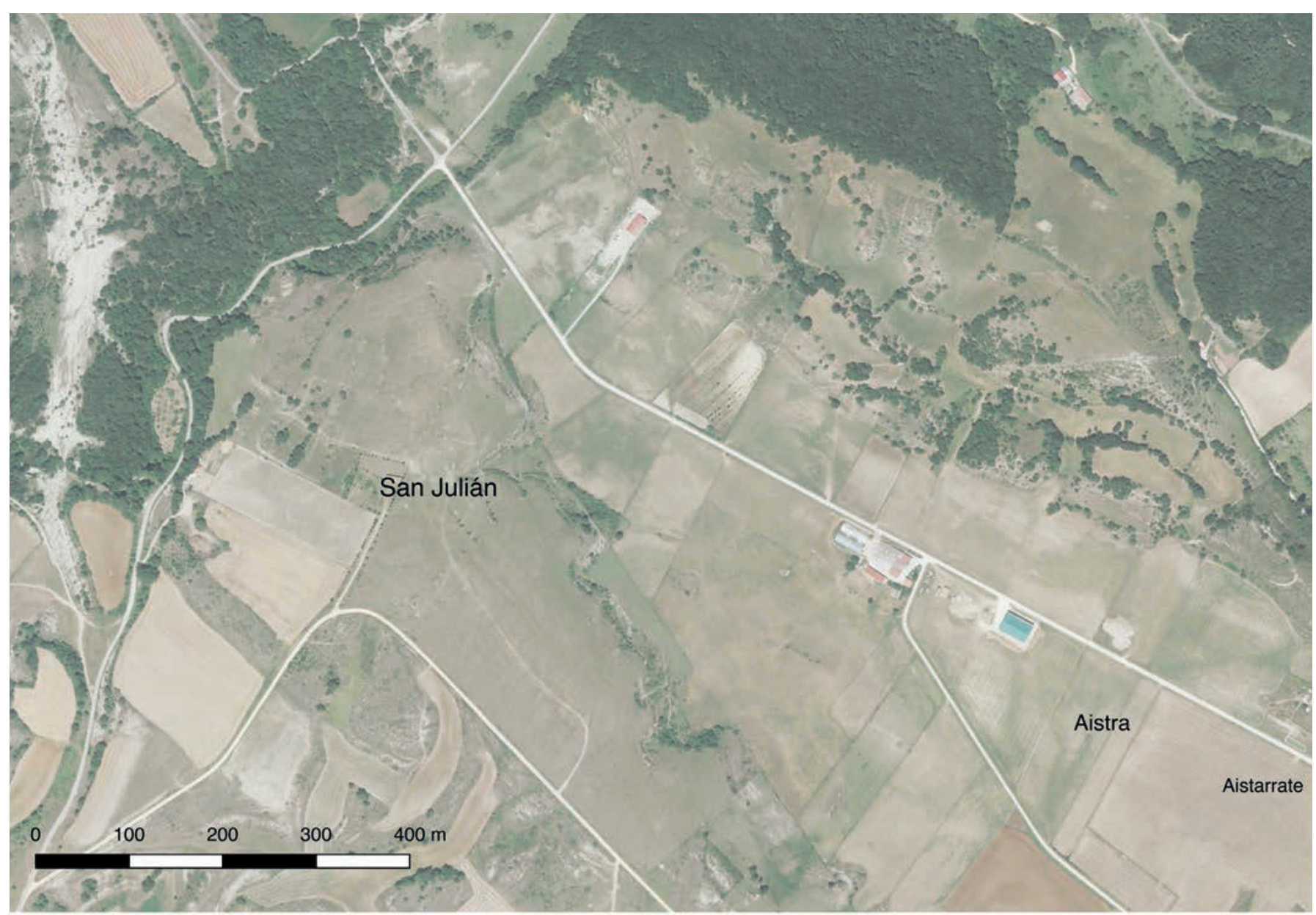

Fig. 2. Fotografía aérea del yacimiento de Aistra (Zalduondo-Araia, Álava). Fondo Ortofoto 2015 del Gobierno Vasco.

silos y estructuras de fondo rehundido que en parte han sido afectadas por el cementerio de la fase posterior.

Hacia el 700 este primer edificio fue completamente desmantelado y en su proximidad se construyó una nueva longhouse (E5) con una orientación casi perpendicular. Se trata de un edificio similar al anterior. $\mathrm{Su}$ planta es rectangular con un extremo semicircular en el este en el que se conserva una roza perimetral destinada probablemente al alojamiento de un muro de tierra reforzado (Fig. 3). El resto de la estructura está delimitada por postes de madera y se ha perdido tanto el extremo occidental como parte del perímetro septentrional como consecuencia del rebaje posterior de la superficie. En términos dimensionales esta construcción es aún mayor que la de la fase anterior (dimensiones estimadas 24 x $10 \mathrm{~m}$ ), y también en esta ocasión son evidentes las huellas de reparaciones. Atendiendo a las dataciones radiocarbónicas obtenidas en los rellenos de los dobles agujeros preservados se puede pensar que la construcción estuvo en uso entre los siglos VIII y al menos una parte del siglo X. Al sur de la longhouse se realizó un amplio cementerio formado por más de medio centenar de tumbas, así como una serie de estructuras dispuestas en torno a un espacio abierto en cuya proximidad se construyó, hacia el 950, la iglesia de San Julián. Debe reseñarse que no se ha hallado ni un solo silo que pueda ser asignado de forma indiscutible a esta fase.

La interpretación funcional de estas construcciones y de sus compartimentaciones está penalizada por el alto grado de arrasamiento del yacimiento, lo que explica que prácticamente no se hayan preservado niveles de ocupación en el interior de las estructuras. ${ }^{16}$ Las medidas de fosfatos de los depósitos son consideradas como uno de los métodos más adecuados para poder reconocer la diversidad de usos y funciones dentro de los espacios domésticos (Zimmermann 1998; Hamerow 2002: 25; Carver 2009: 93 y 162-163). En ausencia de suelos primarios, en Aistra se

\footnotetext{
16 Fenómeno muy común en otros sectores europeos, Gerritsen 1999: 142; Schreg 2012: 253.
} 


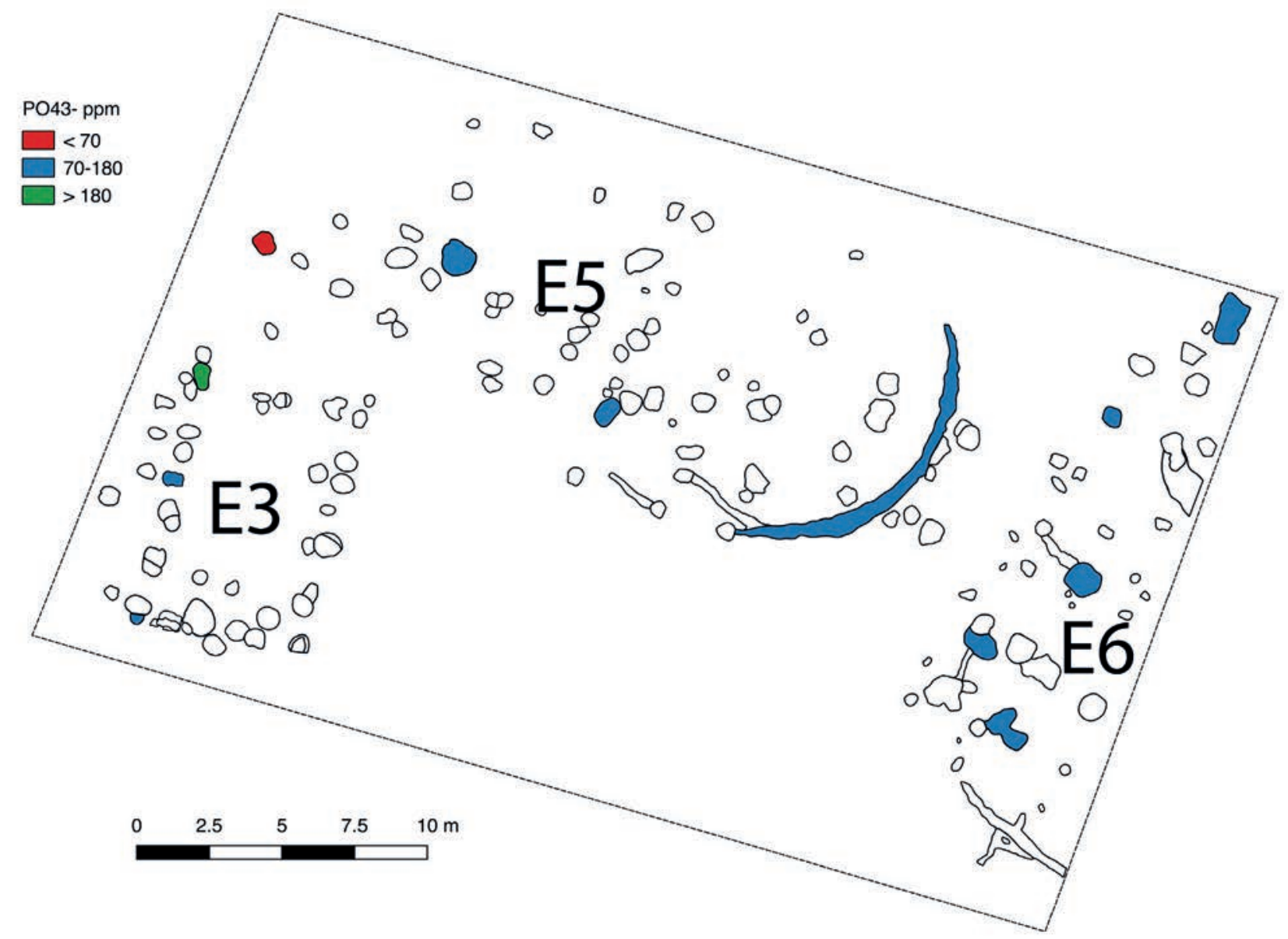

Fig. 3. Planimetría de los valores de fosfatos $\left(\mathrm{PO}_{4}{ }^{3-} \mathrm{ppm}\right)$ de las muestras analizadas de las longhouses E6, E5 de Aistra (Zalduondo-Araia, Álava). Se ha añadido por comparación la estructura E3.

han medido los rellenos de amortización de los agujeros de poste de las dos longhouses (E6, E5) y de un edificio rectangular de la segunda fase (E3), siendo conscientes de los problemas interpretativos que supone analizar este tipo de depósitos ${ }^{17}$. Los valores de $\mathrm{PO}_{4}{ }^{3-}$ (Fig. 3) muestran una sustancial homogeneidad de las medidas obtenidas en las tres estructuras, lo que permite excluir que coexistan usos domésticos y establos bajo el mismo techo. ${ }^{18}$ Teniendo en cuenta los residuos y materiales recuperados en ambas estructuras, se plantea que estas grandes construcciones hayan tenido como función principal la residencial, aunque contasen con compartimentaciones internas destinadas al almacenaje y a la realización de actividades sociales no necesariamente privadas.

\footnotetext{
17 Sobre las medidas de fosfatos en agujeros de poste y sus problemas interpretativos ver Zimmermann 1998, p. 214.

${ }_{18}$ El protocolo seguido para el análisis de fosfatos es el propuesto por Terry et al. 2004. Se agradece a L. A. Ortega su colaboración en la realización de este estudio. La interpretación completa y detallada de estos análisis será realizada en el volumen en preparación sobre Aistra.
}

Para terminar de caracterizar este yacimiento es preciso dedicar algo de atención a los registros bioarqueológicos. ${ }^{19}$ Los patrones de consumo de Aistra permiten sugerir que el centro de San Julián se abastecía de forma regular de cereales, aunque careciese, al menos desde el siglo VIII, de sistemas de almacenamiento subterráneo de reservas estratégicas a largo plazo destinadas a evitar el riesgo. Es posible que algunas de las estructuras halladas, o que incluso uno de los compartimentos de la longhouse, estuviesen destinadas al almacenaje a corto plazo de cereales y de otros productos agrarios.

La fauna recuperada en este yacimiento se caracteriza por una significativa representación de animales salvajes, incluyendo ciervos y corzos, el consumo relevante de animales jóvenes (en particular ovejas y cabras) y el alto porcentaje de cerdos, que es el más elevado de todo el

19 Todo lo referido a los objetos muebles y al análisis social del yacimiento será tratado en la monografía en avanzado estado de preparación en colaboración con A. Reynolds (UCL), al que se agradece la posibilidad de analizar los registros de Aistra. 


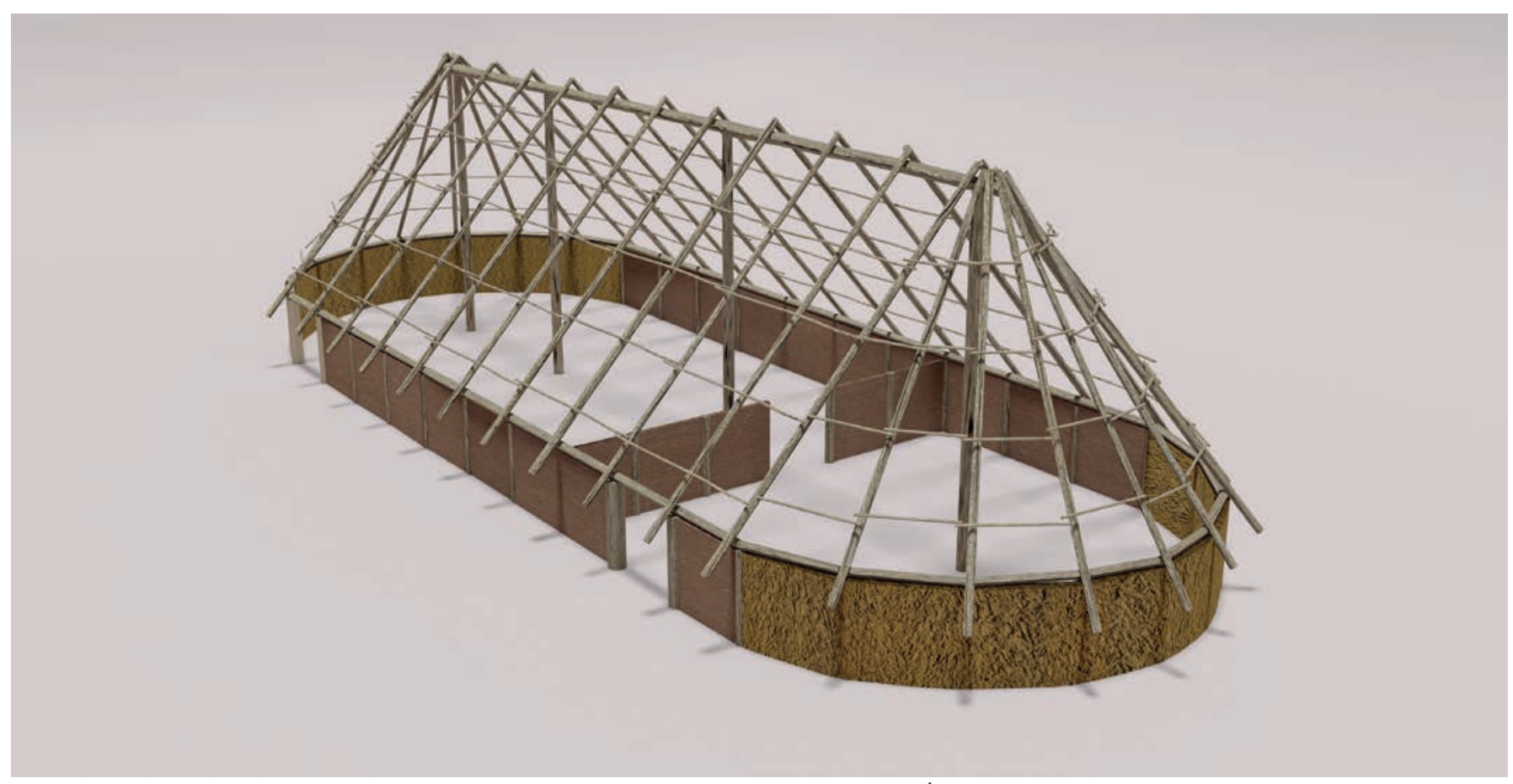

Fig. 4. Infografía con la reconstrucción de la longhouse E5 de Aistra (Zalduondo-Araia, Álava) realizada por Xosé Otero.

territorio (Grau 2015: 75-87; Grau 2016). Los bajos porcentajes de cerdos hallados en los yacimientos rurales altomedievales de buena parte de Europa han llevado a considerar su presencia como un marcador de estatus (Morales 1992; Loveluck 2013), pero en la actualidad se considera que es el consumo de carne en general, y no la del cerdo en particular, lo que permite caracterizar las ocupaciones de alto nivel social (Grau 2017). En definitiva, el perfil de consumo cárnico de Aistra es distinto del de otros yacimientos alaveses e hispanos altomedievales (Grau 2015) y se corresponde con un cuadro propio de élites supralocales que tienen acceso a espacios donde se practica la caza, actividad que define la identidad de este tipo de élites. Además, los habitantes de las longhouses se abastecen regularmente de animales jóvenes criados específicamente para el consumo de carne en otras localidades. No se debería de excluir, por otro lado, que en las longhouses de Aistra se desarrollasen actividades como la redistribución de determinados alimentos o la realización de banquetes colectivos que constituirían las bases para la creación de redes clientelares y el reforzamiento de los poderes locales. Este tipo de prácticas tiene reflejo tanto en la documentación textual (Wickham 2005: 195-196) como material en otros contextos europeos altomedievales (p. e. Loveluck 2013; Sykes 2014: 159 o 161). ${ }^{20}$

\footnotetext{
20 Sobre el papel de los banquetes públicos en los procesos de construcción de comunidades políticas véase ahora Hayden 2014.
}

En definitiva, los dos casos analizados sugieren que las construcciones grandes y alargadas identificadas como longhouses en Álava en la alta edad media se corresponden con espacios domésticos de 'élites menores' o intermedias. Son construcciones complejas, que presentan ciertas similitudes formales, probablemente realizadas por especialistas (Gerritsen 2008: 149) y en las que se ha realizado una importante inversión de capital social (Hamerow 2002: 51). Con ello no se quiere afirmar que necesariamente todas y cada una de este tipo de construcciones deban ser leídas en estos términos en todas las ocasiones (véase p. e. Bianchi 2012: 199), pero al menos en Álava esta interpretación parece ser la que mejor se ajusta a los registros disponibles.

Partiendo de esta constatación se pretende argumentar a continuación que, a través de estos registros domésticos, es posible analizar los procesos de construcción de comunidades sociopolíticas que han tenido lugar en su seno. La comparación de estas longhouses a escala territorial (entre sí y respecto a otras arquitecturas domésticas alavesas), peninsular o continental (mediante el análisis de las residencias de las élites de otros espacios peninsulares o europeos, p. e. Nissen-Jaubert 2010; Hamerow 2010; Santangeli 2011; Thomas 2012) debería permitir el análisis, tanto de la complejidad social interna, como de la amplitud y la articulación de los sistemas sociopolíticos englobantes. Por motivos de espacio se abordará en esta ocasión solamente la primera de estas dos temáticas. 


\section{DISCUSIÓN: BIOGRAFÍA DE LAS CASAS, LONGHOUSES Y SOCIEDADES LOCALES EN ÁLAVA, 700-1000}

Una de las líneas de trabajo más fructíferas que ha desarrollado la arqueología doméstica de la prehistoria reciente en los últimos años ha sido el estudio del ciclo de vida de las casas en relación con las transformaciones de los grupos sociales residentes (Brück 1999; Gerritsen 1999, 2007 y 2008). El concepto de biografía cultural ha sido aplicado al análisis de la temporalidad de la cultura material para afirmar que la perduración de un objeto depende más de factores y significados culturales que de variables técnicas o funcionales, incluso en contextos de obsolescencia planificada. Tomando en consideración varios estudios etnográficos, autores como F. Gerritsen han analizado la correspondencia existente entre el proceso de construcción, uso, ampliación, y abandono o destrucción intencionada de las construcciones domésticas con el proceso de formación, expansión, contracción y desaparición del núcleo familiar original, hasta que las nuevas generaciones reinician el ciclo (Gerritsen 1999). A partir de esta analogía biológica varios especialistas han analizado la transformación de los paisajes sociales de la prehistoria reciente en distintos sectores europeos, en particular en el contexto de la conformación y nucleación de asentamientos estables y dotados de una cierta perduración espacial (Gerritsen 2007). Frente a explicaciones funcionalistas que han analizado el proceso de estabilización y el fin de la movilidad de las construcciones domésticas en la prehistoria reciente en términos de cambios en las prácticas agrarias o de intensificación de la producción (crítica en Fokkens 2003), autoras como J. Bürck han subrayado que la nueva racionalidad que supone el fin de los desplazamientos cíclicos de las construcciones domésticas responde a un complejo proceso de creación de identidades espaciales en un contexto social altamente fluido (Brück 1999). ${ }^{21}$

\footnotetext{
21 Este marco conceptual ha sido también utilizado, desde perspectivas muy diferentes, por A. Blanco González para analizar la emergencia de las longhouses del interior peninsular entre el fin de la Edad del Bronce y el inicio de la Edad del Hierro (1250-800 a C). Fue éste un período en el que se crearon asentamientos rurales estables como resultado de un proceso de la nucleación y estabilización del poblamiento rural. Los asentamientos precedentes estaban constituidos por construcciones efímeras que se desmantelaban y se desplazaban siguiendo ciclos cortos de vida. La implantación de asentamientos estables creó las condiciones para la creación de edificios de larga duración que fueron reconstruidos una y otra vez en el mismo lugar, constituyendo no solamente un instrumento de legitimación de derechos de propiedad, sino también de construcción de comunidades sociopolíticas basadas en la creación de memorias transgeneracionales (Blanco González 2011).
}

Precisamente, si hay un criterio que acomuna la longhouse de Gasteiz con las de Aistra es el de su la larga duración, puesto que cada una de las tres estructuras han sido continuamente reparadas y mantenidas en el mismo lugar durante varias generaciones. Es posible, incluso, que la longhouse de Gasteiz haya sido construida sobre otra construcción similar previa ubicada en la misma posición. La existencia de dobles postes que se cortan entre sí, de reparaciones y la ausencia de ampliaciones $o$ añadidos son rasgos comunes en los dos yacimientos. De hecho, se ha podido estimar que la estructura A1 de Gasteiz ha estado en uso durante un siglo, mientras que las de Aistra han perdurado durante unos dos siglos cada una de ellas, aproximadamente..$^{22}$ Esta constatación es importante porque muestra que la duración de este tipo de construcciones complejas realizadas sobre postes de madera no ha estado determinada por factores funcionales o técnicos, sino sociales.

Si se examinan otros espacios domésticos excavados en extensión en el territorio alavés se observa que esta larga perduración de los edificios es muy poco común en época altomedieval (Fig. 5). Así por ejemplo en Zornoztegi o en Zaballa se ha podido inferir que las estructuras domésticas se reconstruían siguiendo ciclos cortos de vida, quizás de una o dos generaciones, manteniéndose como elementos de estabilidad espacial más legibles en el espacio doméstico la ubicación plurisecular de los lugares de almacenamiento. De hecho, el estudio antracológico y estratigráfico muestra que las construcciones sobre postes de las viviendas y construcciones ordinarias se desmontaban y raramente se reparaban o se ampliaban (p. e. Alfaro 2012). Este fenómeno se ha observado, asimismo en numerosas aldeas altomedievales peninsulares, como es el caso de La Mata del Palomar o de Gózquez en el interior peninsular (Tejerizo 2013; Vigil-Escalera 2015) ${ }^{23}$ Es particularmente interesante este último caso de estudio, en el que se ha podido observar que son la parcelación, los campos de cultivo y el cementerio los únicos referentes espaciales que perduran durante todo el ciclo de vida de la aldea, mientras que las parcelas domésticas fueron transformadas regularmente.

No obstante, tanto en Zornoztegi como en Zaballa también hay ejemplos concretos de construcciones domésticas que han tenido una mayor perduración respecto

\footnotetext{
22 En contraste, la longhouse de Poggibonsi no parece mostrar evidencias de reparaciones significativas y parece que estuvo en uso durante pocas generaciones (Fronza 2005: 141-203).

23 Este es el patrón más común observado también en otros sectores europeos; p. e. Heidinga 1987: 32; Hamerow 2002: 33-37.
} 


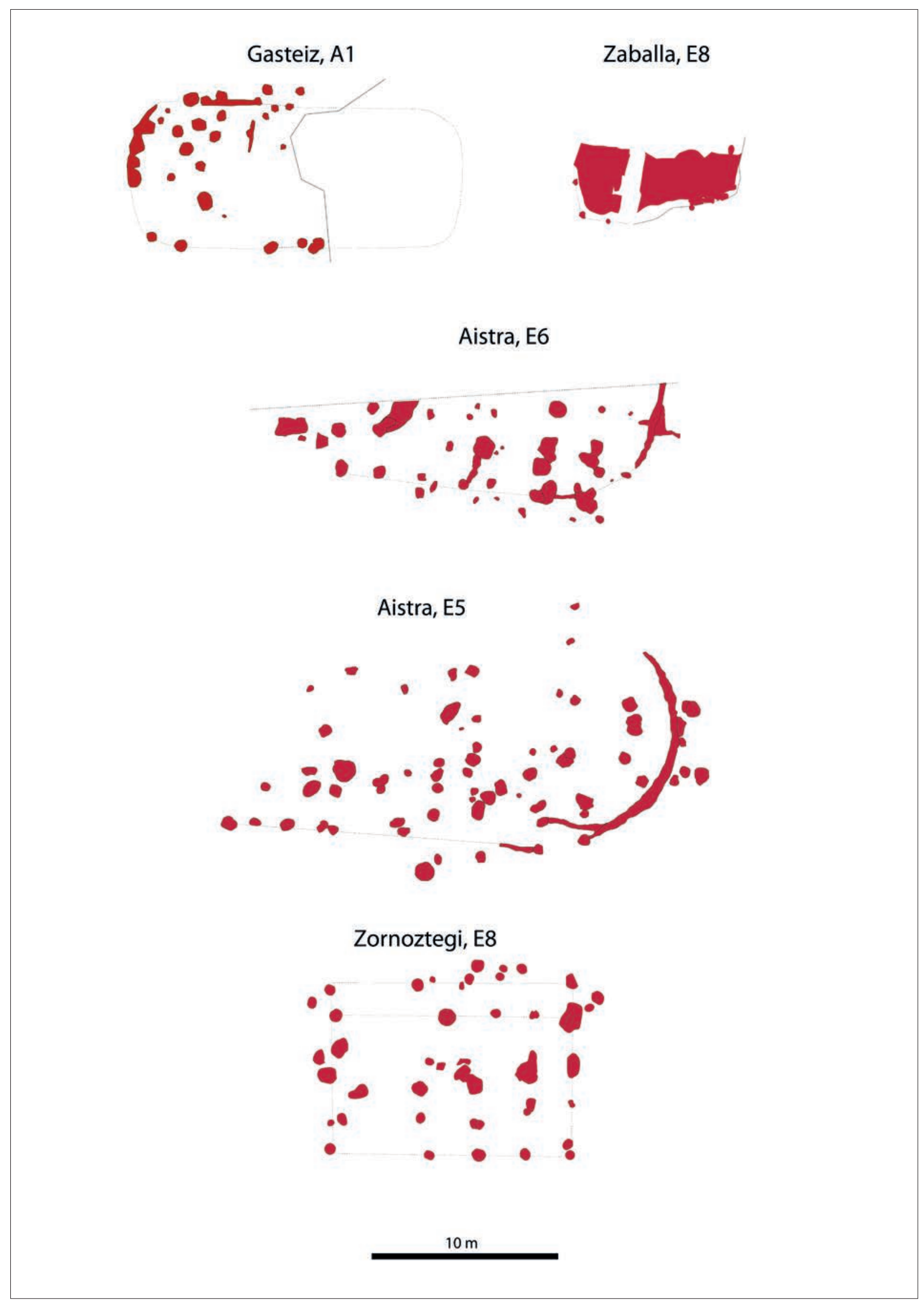

Fig. 5. Plantas de las estructuras domésticas de larga duración de Gasteiz, Aistra, Zornoztegi y Zaballa representadas a la misma escala. 
al resto. Este es el caso de la construcción E8 de Zornoztegi, una estructura rectangular de notables dimensiones $(12 \times 8 \mathrm{~m})$, pero no alargada, que estuvo en uso desde el siglo IX hasta el XI. Los patrones de consumo que se infieren a partir de los materiales recuperados o las características de los silos asociados no muestran la existencia de diferencias sociales sensibles respecto al resto de las ocupaciones de la aldea. Algo parecido podría decirse respecto a la construcción E6-E8 de Zaballa, en uso durante el siglo IX y mediados del X, y que fue posteriormente arrasada por la construcción de una iglesia. En este caso se trata de una estructura de dimensiones medias $(9 \times 4 \mathrm{~m})$, poco mayor que otras construcciones domésticas del yacimiento (Alfaro 2012). Tampoco en esta ocasión ha sido posible reconocer patrones de consumo diferenciados respecto al resto del asentamiento.

La permanencia y estabilidad de las longhouses, en el caso de Gasteiz y de Aistra, o de construcciones domésticas grandes o medianas, en el caso de Zornoztegi y Zaballa, determina que estas estructuras hayan tenido un papel relevante en la construcción de un determinado orden espacial y social en un contexto fluido como es el de la conformación de las aldeas y asentamientos estables que se están conformando en la llanada alavesa en un proceso que arranca entre el siglo VII y el VIII. Mientras que las unidades domésticas del campesinado se reelaboran siguiendo ciclos generacionales, las longhouses y las construcciones grandes y medianas han sido instrumentos de construcción de identidades sociopolíticas en el contexto de la reconfiguración o de creación de comunidades locales mediante la construcción de una memoria social (Fentress y Wickham 2003). En otras palabras, el hallazgo de este tipo de construcciones no constituye un mero reflejo pasivo de la existencia de comunidades locales internamente diversificadas, sino que son instrumentos básicos en la construcción de sistemas sociopolíticos a escala local y supralocal.

Aistra proporciona quizás el ejemplo más significativo para analizar este proceso. A pesar de haber realizado prospecciones geofísicas extensivas, no se ha localizado un espacio funerario que pueda ser fechado con seguridad entre los siglos VI y VII, cuando estuvo en uso la primera longhouse. En un medio espacial polinuclear la longhouse constituye un elemento de referencia espacial multigeneracional, seguramente en competición con otros, en el que se construye la memoria social de una comunidad y se desarrollan prácticas como los banquetes colectivos de alto valor sociopolítico. Hacia el 700, cuando se construye la segunda longhouse y se configura la red aldeana de la llanada alavesa, este sector de Aistra (San Julián) se conforma como el eje principal de articulación político, capaz de unir en un mismo espacio los dos instrumentos básicos de construcción de la memoria social colectiva: el cementerio ${ }^{24}$ y la longhouse. ${ }^{25}$ Por ello no resulta nada extraño que fuese precisamente en Aistra donde se construyese 250 años después una de las primeras iglesias rurales conocidas de toda la llanada alavesa en el siglo X. La construcción de la iglesia de San Julián tuvo lugar en el mismo momento que se produjo el desmantelamiento de la segunda longhouse, por lo que podría sugerirse que el capital simbólico y social de esta longhouse se transfirió a esta construcción de culto en un nuevo contexto sociopolítico legitimado esta vez por la Iglesia (Fig. 6). ${ }^{26}$

En definitiva, creo que se puede afirmar que, a pesar de su dificultad interpretativa, las arquitecturas domésticas altomedievales no tienen por qué ser menos elocuentes que los cementerios, las iglesias u otros registros a la hora de analizar la complejidad social en la alta edad media. El análisis de la biografía de las casas combinado con el estudio de los patrones de consumo doméstico y la valoración de la inversión técnica, social y simbólica empleada en la realización de las construcciones constituyen, al menos en la llanada alavesa, marcadores de complejidad social que permiten realizar análisis sociales densos, incluso en términos comparativos. ${ }^{27}$ Mientras que los residentes de las casas grandes de Zornoztegi o Zaballa podrían caracterizar élites aldeanas, quizás conformadas por campesinos enriquecidos que habrían logrado obtener y mantener una posición de relevancia en el seno de las comunidades locales, ${ }^{28} \mathrm{se}$ podría sugerir que la escala de acción política y social de las familias residentes en Gasteiz y en Aistra superan el ámbito local, de tal forma que tienen acceso a recursos $\mathrm{y}$ redes de intercambio supralocales.

\footnotetext{
24 A partir de la notable variabilidad de los patrones alimentarios de los individuos enterrados en Aistra en los siglos VIII-X (Quirós Castillo 2013a) podría sugerirse que, en este cementerio, carente de iglesia, se enterró el conjunto de la comunidad de Aistra, y no solo los habitantes de la longhouse y los espacios anexos. Sobre la alimentación del cementerio de Aistra véase ahora Lubritto et al. 2017.

25 Es importante, a este propósito, señalar que no son muy abundantes los espacios funerarios conocidos en la llanada alavesa fechables entre los siglos VIII y X (p. e. Dulantzi, Larrara, Arkaia).

26 Sobre la escasa presencia de Iglesias en la llanada alavesa antes del siglo XI, Sánchez Zufiaurre 2007: 318-319.

27 La larga duración de las construcciones domésticas ha sido reconocida como uno de los principales rasgos que caracteriza las residencias de élites en la alta edad media en varios contextos europeos (p. e. Klápště y Nissen Jaubert 2007: 89; Hamerow 2010: 64; Gardiner 2016: 327).

${ }_{28}$ Véase el caso de Bagaudano y Faquilona en el siglo X en Liébana (Portass 2017: 66-96).
} 


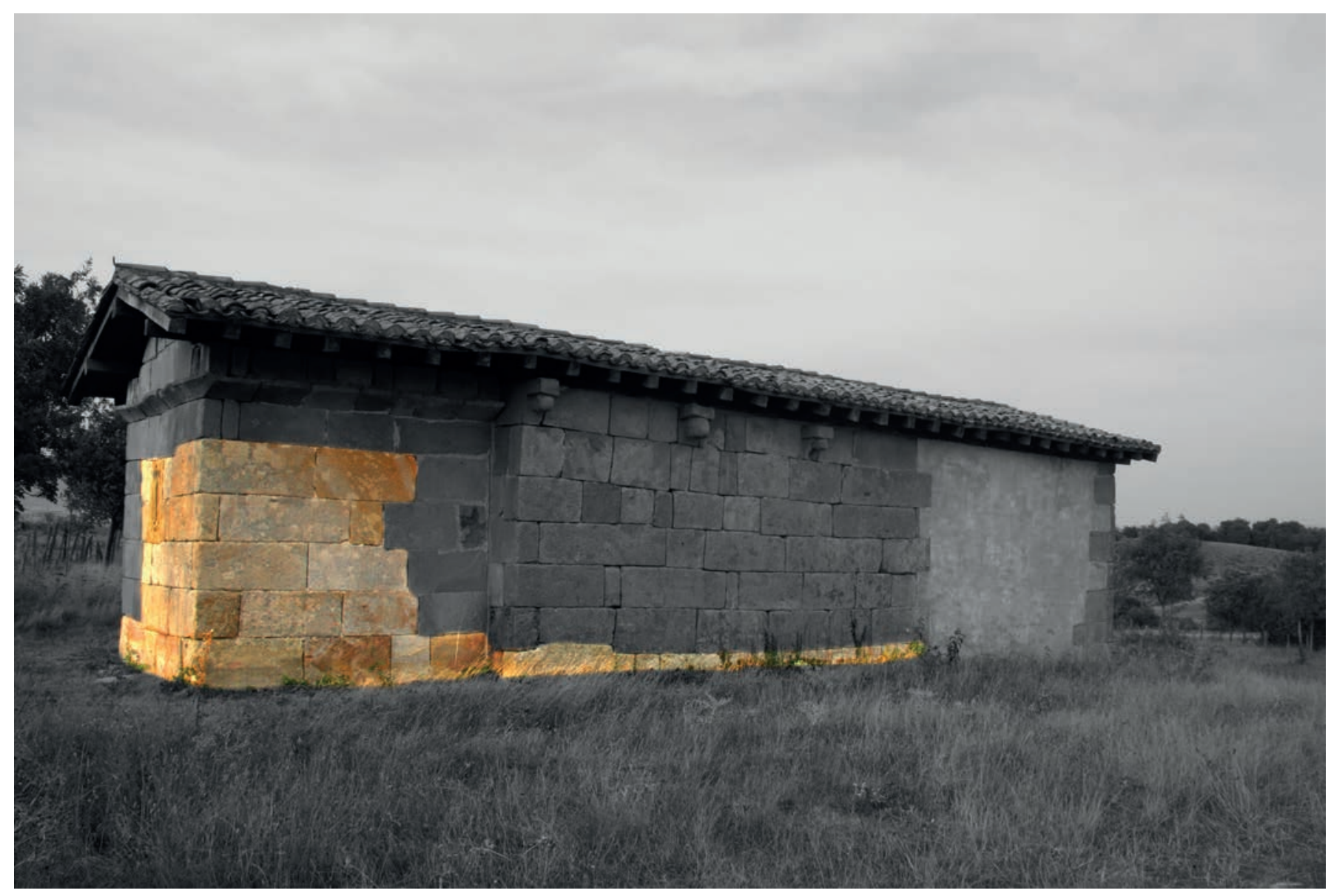

Fig. 6. Iglesia de San Julián y Santa Basilisa de Aistra (Zalduondo-Araia, Álava), fundada a mediados del siglo X.

Por otro lado, tal y como se ha señalado en un trabajo reciente (Quirós Castillo e. p.), la emergencia de estas construcciones domésticas de larga duración permite analizar a escala local los diferentes recorridos sociales y políticos que han tenido los distintos asentamientos. En Gasteiz, donde el proceso formativo de la comunidad rural parece que puede remontarse al siglo VII (Cabrerizo y Cardoso 2009), la realización de la longhouse en el siglo IX podría ser el resultado de un proceso de complejización social interna antes que una imposición externa que se manifiesta en la ampliación y/o transformación de la primera fase de la unidad doméstica hallada en el área de la Catedral. En cambio, en el caso de Aistra la primera longhouse (E6) es la estructura doméstica más antigua reconocida hasta el momento en el lugar de San Julián, y podría constituir el elemento fundante de este núcleo. $\mathrm{Si}$ nuestra propuesta interpretativa es correcta, ambos yacimientos mostrarían caminos muy diferentes en términos de agencia y desarrollo sociopolítico interno. Esta diversidad se documenta también en Zornoztegi y en Zaballa, puesto que la estructura E8 es también la más antigua reconocida en la aldea de Zornoztegi, mientras que la E6 de Zaballa no parece que pueda ser fechada en el primer momento de conformación de la comunidad aldeana.

La movilidad social a escala local raramente tiene reflejo en la documentación textual, ${ }^{29}$ de tal forma que cuando las élites aldeanas aparecen en los textos es cuando precisamente cuentan con una posición ya consolidada y realizan donaciones y actos destinados a conectarse con agentes políticos externos, tal y como ocurre con algunos presbíteros, saiones o merinos activos en el occidente alavés (Quirós Castillo y Santos Salazar 2012). En cambio, los documentos son más elocuentes a la hora de caracterizar los poderes supralocales que se van articulando, al menos desde el siglo IX, también en el occidente alavés. El caso del abad Avito, promotor a inicios de este siglo de la construcción de la iglesia de San Román de Tobillas y que contaba con bienes y derechos en una serie de aldeas localizadas en torno a esta localidad (Larrea 2007), muestra la escala en la que actuaban estas élites rurales intermedias,

\footnotetext{
${ }^{29}$ Véase Portass 2017.
} 
que quizás puedan ser confrontables con los residentes en las longhouses de la llanada alavesa. En un cuadro de esta naturaleza seguirían todavía faltando las aristocracias territoriales, que se hacen patentes en la documentación sobre todo a partir del último cuarto del siglo IX (como es el caso de Arroncio y su familia, o los Vela), pero que aparentemente todavía no son reconocibles en el registro doméstico, pero sí en la arquitectura monumental.

En definitiva, la estabilidad y la duración de las construcciones domésticas principales, las "casas", en un medio fluido como el de las sociedades altomedievales constituye un instrumento básico, pero no el único, para la construcción de un orden social jerárquico y articulado a varias escalas en el marco de la construcción y reconfiguración de las comunidades políticas que dan lugar a las aldeas y a los poderes fragmentados que dominan el paisaje alavés en este período. En este contexto la longhouse es un instrumento de empoderamiento que utilizan las élites emergentes o fundantes para construir una memoria social sobre la que se legitima un nuevo orden social y una serie de derechos en la esfera local y supralocal.

\section{CONCLUSIONES}

Las estructuras que han sido clasificadas como longhouses en el noroeste de la península ibérica son sustancialmente construcciones grandes alargadas, sin que se haya detectado la presencia de espacios dedicados al ganado en su interior, y siempre parecen contar con estructuras auxiliares próximas. Por este motivo los especialistas han sugerido que su función sería principalmente residencial. $\mathrm{Y}$ aunque la tensión entre forma, función y significado social es fundamental a la hora de definir esta categoría arqueológica, el uso que se hace de ella en el sur de Europa es puramente morfológico. En este trabajo se ha pretendido realizar una lectura social de este tipo de construcciones, pero esta interpretación tiene una validez únicamente contextual y no debiera de generalizarse.

Por lo que se refiere a la interpretación social de estos hallazgos, son varios los autores que han alertado acerca del riesgo que supone establecer una conexión inmediata entre el estatus social y las dimensiones de las construcciones domésticas (Hamerow 2002: 89-93; Ulmschneider 2010: 161). No cabe duda de que este debe ser un criterio más para caracterizar residencias de élites activas a distintas escalas (p. e. Steadman 2015: 223 y ss.), pero contamos con suficientes evidencias arqueológicas (Moore 2012) o etnoarqueológicas (Guidoni 1989) para saber que hay otras interpretaciones y usos posibles. De hecho, la interpretación social de estas arquitecturas domésticas pasa por la realización de análisis comparativos a escala territorial y de estudios contextuales que analicen criterios como los patrones de consumo o la dimensión ideológica y sociológica del espacio doméstico (Peytremann 2012: 222-223; Loveluck 2013; Burnouf y Catteddu 2015: 49-50). Este trabajo pretende ser un primer paso en esta dirección, pero quedan pendientes muchos retos. Entre ellos, comparar el universo material de las longhouses del País Vasco con las arquitecturas domésticas realizadas en piedra o en técnicas mixtas en otros sectores de la península ibérica, en particular allí donde residan 'elites intermedias' como las analizadas en este trabajo. Es necesario, asimismo, poder analizar el caso alavés con otros sectores del noroeste peninsular. Resulta paradójico constatar que sea en el País Vasco, territorio considerado tradicionalmente como uno de los espacios menos desarrollados en términos sociales y políticos en el noroeste y periférico respecto a los poderes centrales, donde se ubiquen todas las "casas grandes" y las longhouses conocidas hasta el momento. El atronador silencio de otras regiones del noroeste probablemente sea más el resultado del estado de los estudios sobre la arquitectura doméstica que un reflejo real de las presencias y ausencias.

Por último, hay que señalar que, desde un punto de vista meramente morfológico, no parece haber una filiación tipológica o formal estrecha y directa entre las longhouses hispanas y las del norte o noroeste europeo en la alta edad media, por lo que no parece procedente recurrir a interpretaciones culturalistas o étnicas (Ariño 2013: 107; Reynolds 2015: 171). ${ }^{30}$ Quizás sería más oportuno, en vez de concentrar nuestros esfuerzos en identificar paralelos que pueden resultar erráticos, poner la atención sobre lo que ocurre a escala subregional. En definitiva, cabe preguntarse hasta qué punto sea necesario u oportuno recurrir a este neologismo en la literatura arqueológica hispana, puesto que, en rigor, estamos tratando más con "casas grandes alargadas" que con longhouses en sentido propio. ${ }^{31}$

\section{AGRADECIMIENTOS}

Este trabajo ha sido realizado en el marco del Proyecto "Agencia campesina y complejidad sociopolítica en el noroeste de la Península Ibérica en época medieval"

\footnotetext{
30 En contra Bianchi 2012: 205.

31 De hecho, hay autores que evitan explícitamente el término, como Nissen Jaubert 2010; Schreg 2012 o Loveluck 2013, o que cuestionan su uso, Rosberg 2013.
} 
(Ministerio de Economía, Industria y Competitividad, AEI/FEDER UE HUM2016-76094-C4-2-R), del Grupo de Investigación en Patrimonio y Paisajes Culturales (Gobierno Vasco, IT936-16) y del Grupo de Estudios Rurales (Unidad Asociada UPV/EHU-CSIC). Las medidas de fosfatos han sido realizadas por Luis Ángel Ortega (UPV-EHU) y la reconstrucción gráfica ha sido realizada por Xosé Otero. Agradezco a la empresa Strato el acceso a la documentación de la intervención realizada en el importante yacimiento de Guaya (Ávila). Los revisores del texto, Alfonso Vigil-Escalera e Igor Santos han contribuido notablemente a mejorar este texto.

\section{BIBLIOGRAFÍA}

Agustí García, E., Morín de Pablos, J., Urbina Martínez, D., López Fraile, J. L., Sanabria Marcos, J., López López, G., López Recio, M., Illán Illán, J. M., Yravedra Sainz de los Terreros, J. y Montero I. 2012: "El yacimiento de Las Camas (Villaverde, Madrid). Longhouses en la Meseta Central", en J. Morín de Pablos y D. Urbina Martínez (eds.), El Primer Milenio A C en la Meseta Central. De la longhouse al oppidum, vol. 1, pp. 112-147. Audema, Madrid.

Alcock, N. W. y Smith, P. 1972: "The Long-house: a plea for clarity", Medieval Archaeology, 16, pp. 145-146.

Alfaro Suescun, E. 2012: "La arquitectura de Zaballa: materiales y técnicas constructivas", en J. A. Quirós Castillo (dir.), Arqueología del campesinado medieval: la aldea de Zaballa, pp. 493-529. Universidad del País Vasco, Bilbao.

Arce, J. 2011: Esperando a los árabes. Los visigodos en Hispania (507-711). Marcial Pons, Madrid.

Ariño, E. 2013: "El hábitat rural en la Península Ibérica entre finales del siglo IV y principios del VIII: un ensayo interpretativo", Antiquité Tardive, 21, pp. 93-123, doi: https://doi.org/10.1484/j.at.5.101406.

Armstrong Oma, K. 2016: "Long time-Long house", en F. Iversen y H. Peterson (eds.), The agrarian life of the North 2000 BC-AD 1000. Studies in rural settlement and farming in Norway, pp. 11-25. Portal Academi, Kristiansand.

Azkarate, A., García, I. y Solaun, J. L. 2013: “El asentamiento altomedieval de Gasteiz", en A. Azkarate y J. L. Soluan (eds.), Arqueología e Historia de una ciudad. Los orígenes de Vitoria-Gasteiz, pp. 399-446. Universidad del País Vasco, Bilbao.

Azkarate, A. y Quirós Castillo, J. A. 2001: “Arquitectura doméstica altomedieval en la Península Ibérica. Reflexiones a partir de las excavaciones arqueológicas de la Catedral de Santa María de Vitoria-Gasteiz, País Vasco", Archeologia Medievale, 28, pp. 25-60.

Azkarate, A. y Solaun, J. L. 2012: “Tipologías domésticas y técnicas constructivas en la primitiva Gasteiz (País Vasco) durante los siglos VIII al XII d. C.", Arqueología de la Arquitectura, 9, pp. 103-128, doi: https://doi. org/10.3989/arqarqt.2012.10010.

Azkarate, A. y Solaun, J. L. 2013: Arqueología e Historia de una ciudad. Los orígenes de Vitoria-Gasteiz. Universidad del País Vasco, Bilbao.

Azkarate, A. y Solaun, J. L., 2015: "Espacios domésticos, urbanos y rurales, de época medieval en el País Vasco", en M. E. Díez Jorge y J. Navarro Palazón (eds.), La casa medieval en la Península Ibérica, pp. 541-576. Sílex, Madrid.

Beck, R. A. (ed.) 2007: The Durable House: House Society Models in Archaeology. Southern Illinois University, Carbondale.

Bianchi, G. 2012: "Building, inhabiting and "perceiving" private houses in early medieval Italy", Arqueología de la Arquitectura, 9, pp. 195-212, doi: https://doi.org/10.3989/arqarqt.2012.11605.
Bianchin Citton, E., Persichetti, A. y Rigato, C. 2012: "Megliadino S. Vitale: trace insediative di età altomedievale", Notiziario di Archeologia del Veneto, 1 , pp. 22-28.

Blanco-González, A. 2011: "From huts to 'the house': the shift in perceiving home between the Bronze Age and the Early Iron Age in Central Iberia (Spain)", Oxford Journal of Archaeology, 30.4, pp. 393-410, doi: https:// doi.org/10.1111/j.1468-0092.2011.00373.x.

Bogaard, A. 2017: "The Archaeology of food surplus", World Archaeology, 49.1, pp. 1-7, doi: https://doi.org/10.1080/00438243.2017.1294105.

Brena, N. y Hamerow, H. 2015: "An Anglo-Saxon Great Hall Complex at Sutton Courtenay/Drayton, Oxfordshire: A Royal Center of Early Wessex?", Archaeological Journal, 172.2, pp. 325-250, doi: https://doi.org/10 $.1080 / 00665983.2015 .1010369$.

Brogiolo, G. P. y Cagnana, A. 2012: Archaeologia dell'architettura. Metodi e interpretazioni. All'Insegna del Giglio, Firenze.

Brogiolo, G. P. y Chavarria, A. 2005: Aristocrazie e campagne nell'Occidente da Costantino a Carlo Magno. All'Insegna del Giglio, Firenze.

Brück, J. 1999: "House, Lifecycles and Deposition on Middle Bronze Age. Settlements in Southern England", Proceedings of the Prehistoric Society 65, pp. 145-166, doi: https://doi.org/10.1017/ S0079497X00001973.

Brück, J. 2000: "Settlement, Landscapes and Social Identity: the Early-Bronze Age transition in Wessex, Sussex and the Thames Valley", Oxford Journal of Archaeology, 19.3, pp. 273-300, doi: https://doi.org/10.1111/14680092.00110.

Burnouf, J. y Catteddu, I. 2015: Archéologie du Moyen Âge. Editions OuestFrance, Paris.

Caballero Zoreda, L. 1989: "Pervivencia de elementos visigodos en la transición al mundo medieval. Planteamiento del tema”, en III Congreso Nacional de Arqueología Medieval Española, Oviedo, vol 1, pp. 111-134. Asociación Española de Arqueología Medieval, Madrid

Caballero Zoreda, L. 2013: "Producciones constructivas y decorativas. Indicadores cronológico-culturales de la alta Edad Media hispánica", Archivo Español de Arqueología, 86, pp. 187-214, doi: https://doi.org/10.3989/ aespa.086.013.011.

Cabrerizo Benito, K. y Cardoso Tostado, J. 2009: “Aproximación al poblamiento de Gasteiz a través de las excavaciones en la Plaza de la Virgen Blanca", Estudios de Arqueología Alavesa, 24, pp. 401-418.

Campos, T. 2015: Intervención arqueológica al norte de la iglesia de la Inmaculada Concepción, Gorliz (Bizkaia): los niveles de hábitat altomedievales, Trabajo Fin de Master inédito, Universidad del País Vasco.

Carver, M. 2009: Archaeological investigation. Routledge, Oxon.

Castaños, P. 2013: "Estudio arqueozoológico del asentamiento de Gasteiz (siglos VIII-XII d.C.)", en A. Azkarate y J. L. Soluan (eds.), Arqueología e Historia de una ciudad. Los orígenes de Vitoria-Gasteiz, pp. 295-326. Universidad del País Vasco, Bilbao.

Collavini, S. M. 2007: "Spazi politici e irraggiamento sociale delle élites laiche intermedie (Italia centrale, secoli VIII-X)", en P. Depreux, F. Bougard y R. Le Jan (eds.), Les élites et leurs espaces. Mobilité, rayonnement, domination (du Vie au XIe siècle), pp. 319-340. Brepols, Turnhout.

Cutting, M. 2006: "More than one way to study a building: approaches to prehistoric household and settlement space", Oxford Journal of Archaeology, 25.3, pp. 225-246, doi: https://doi.org/10.1111/j.1468-0092.2006.00259.x.

Chapelot, J. y Fossier, R. 1980: Le village et la maison au Moyen Age. Hachette, Paris.

Davies, W. 2016: Windows on Justice in Northern Iberia, 800-1000. Routledge, Oxon.

De Hingh, A. y Bakels, C. 1996: "Paleoabotanical evidence for social difference? The example of the early medieval domain of Serris-Les Ruelles, France", Vegetation History and Archaeobotany, 5, pp. 117-120, doi: https://doi.org/10.1007/bf00189441.

Díez Jorge, M. E. y Navarro Palazón, J. (eds.) 2015: La casa medieval en la península ibérica. Sílex, Madrid.

Donat, P. 1980: Haus, Hof und Dorf in Mitteleuropa vom 7. bis 12. Jahrhundert: archäologische Beiträge zur Entwicklung und Struktur der bäuerlichen Siedlung. Akademie Verlag, Berlin. 
Estrada García, R. 2014: "Excavaciones arqueológicas en la ampliación del Museo de Bellas Artes de Asturias", en Intervenciones Patrimonio Cultural Asturiano 2007-2014, pp. 192-215. Gea, Oviedo.

Fentress, J. y Wickham, C. 2003: Memoria social. Cátedra, Madrid.

Flores Fernández, R. y Sanabria Marcos, P. J. 2012: "La Cuesta, Torrejón de Velasco (Madrid): un hábitat singular en la I Edad del Hierro", en J. Morín de Pablos y D. Urbina Martínez (eds.), El Primer Milenio A C en la Meseta Central. De la longhouse al oppidum, vol. 1, pp. 150-171. Audema, Madrid.

Fokkens, H. 2003: "The longhouse as a central element in Bronze Age daily life", en J. Bourgeois, I. Bourgeois y B. Charette, Bronze Age and Iron Age Communities in North-Western Europe, pp. 9-38. Koninklijke Vlaamse Academie, Bruselas.

Francovich, R. y Valenti, M. (eds.) 2006: IV Congresso Nazioanle di Archeologia Medievale. All'Insegna del Giglio, Firenze.

Francovich, R. y Valenti, M. 2007: Poggio Imperiale a Poggibonsi. Il territorio, lo scavo, il parco. Electa, Milano.

Fronza, V. 2005: Edilizia in materiale deperibile nell'altomedioevo italiano. Tesi di dottorato inedita, Università degli Studi di Siena, Siena.

Fronza, V. 2011: "Edilizia in materiali deperibili nell'alto medioevo italiano: metodologia e casi di studio per un'agenda di ricerca", Post-Classical Archaeologies, 1, pp. 95-138.

Galetti, P. (ed.) 2010: Edilizia residenziale tra IX-X secolo. Storia e archeologia. All'Insegna del Giglio, Firenze.

García de Cortázar, J. A. 1997: "El espacio cántabro-castellano y alavés en la época de Alfonso II el Casto", Cuadernos de Historia de España, 74, pp. 101-120.

García de Cortázar, J. A. 2005: Investigaciones sobre Historia Medieval del País Vasco (1965-2005). Bilbao.

Gardiner, M. 2014: "The Distribution and Adoption of the Byre-House (Longhouse) in Late Medieval Britain", en Medieval Europe in Motion. In Honour of Jan Klápště, pp. 145-162. Archeologický ústav AV ČR, Praga.

Gardiner, M. 2016: "Conceptions of domestic space in the long term- the example of the English medieval hall", en M. S. Kristiansen, E. Roesdahl y J. Graham-Campbell (eds.), Medieval Archaeology in Scandinavia and Beyond: History, trends and tomorrow, pp. 313-333. Aarhus University Press, Aarhus.

Gelichi, S. y Librenti, M. 1997: 'L'edilizia in legno altomedievale nell'Italia del Nord: alcune osservazioni”, Congresso Nazionale di Archeologia Medievale, pp. 215-220. All'Insegna del Giglio, Firenze.

Gerritsen, F. A. 1999: "The cultural biography of Iron Age houses and longterm transformation of settlement patterns in southern Netherlands", en C. Fabech y J. Ringtued (eds.), Settlement and Landscapes, pp. 139-148. Jutland Archaeological Society, Aarhus.

Gerritsen, F. A. 2007: "Relocating the House: Social Transformation in Late Prehistoric Northern Europe", en R. A. Beck (ed.), The Durable House. House Society Models in Archaeology, pp. 154-174. Southern Illinois University, Carbondale.

Gerritsen, F. A. 2008: "Domestic times: houses and temporalities in Late Prehistoric Europe", en A. Jones (ed.), Prehistoric Europe. Theory and Practice, pp. 143-161. Oxford University Press, Oxford.

Gillespie, S. D. 2007: "When is a House?", en R. A. Beck (ed.), The Durable House. House Society Models in Archaeology, pp. 25-50. Southern Illinois University, Carbondale.

González Fernández M. L. Ed., 2009: 'El Pelambre’Villaornate, León. El horizonte Cogotas I de la Edad del Bronce y el periodo Tardoantiguo en el valle medio del Esla. Tragsa, Madrid.

González González, J. M. 1994: “Interpretación arqueológica de un 'campo de hoyos' en Forfoleda (Salamanca)", Zephyrus, 46, pp. 309-313.

Grau, I. 2015: The Zooarchaeology of Alava in its medieval context. British Archaeological Reports, Oxford.

Grau, I. 2016: "Faunal remains and social inequality in the Basque Country during the Early Middle Ages", en J. A. Quirós Castillo (ed.), Social complexity in Early Medieval rural communities, pp. 47-58. Archaeopress, Oxford.

Grau, I. 2017: "Socio-economic status and religious identity in medieval Iberia: The zooarchaeology evidence", Environmental Archaeology, 22.2, pp. 189-199, doi: https://doi.org/10.1080/14614103.2016.1153818.
Guidoni, E. 1989: Arquitectura primitiva. Aguilar / Asuri, Madrid.

Gutiérrez González, J. A. 2003: Peñaferruz (Gijón). El castillo de Curiel y su territorio. Ayuntamiento de Gijón, Gijón.

Gutiérrez Lloret, S. 2012: "Gramática de la casa. Perspectivas de análisis arqueológicos de los espacios domésticos medievales en la Península Ibérica (siglos VII-XIII)", Arqueología de la Arquitectura, 9, pp. 139-164, doi: https://doi.org/10.3989/arqarqt.2012.11602.

Gutiérrez Lloret, S. y Grau I. (eds.) 2013: De la estructura doméstica al espacio social. Lecturas arqueológicas del uso social del espacio. Universidad de Alicante, Alicante.

Halstead, P. 1989: "The economy has a normal surplus: economic stability and social change among early farming communities of Thessaly, Greece", en P. Halstead y J. O'Shea (ed.), Bad year economics: cultural responses to risk and uncertainty, pp. 68-80. Cambridge University Press, Cambridge.

Hamerow, H. 2002: Early Medieval Settlements. The Archaeology of Rural Communities in North-West Europe 400-900. Oxford University Press, Oxford.

Hamerow, H. 2010: "Herrenhöfe in Anglo-Saxon England", Settlement and Coastal Research in the Southern North Sea Region, 33, pp. 59-67.

Hamerow, H. 2012: Rural Settlements and Society in Anglo-Saxon England. Oxford University Press, Oxford.

Hastorf, C. A. y Foxhall, L. 2017: "The social and political aspects of food surplus", World Archaeology 49.1, doi: https://doi.org/10.1080/00438243 .2017 .1252280

Hayden B. 2014: The Power of Feasts: From Prehistory to the Present. Cambridge University Press, Cambridge.

Heidinga, H. A. 1987: Medieval Settlement and Economy North of the Lower Rhine. Archaeology and history of Kootwijk and the Veluwe (the Netherlands). Van Gorcum, Assen/Maastricht.

Hurst, J. G. 1971: "A Review of Archaeological Research (to 1968)", en M. Beresford y J. G. Hurst (ed.), Deserted Medieval Villages, pp. 76-144. Lutterworth Press, Guilford and London.

Joyce, R. A. y Gillespie, S. D. (eds.) 2000: Beyond Kindship: Social and Material Reproduction in House Socities. University of Pennsylvania Press, Philadelphia.

Klápště, J. y Nissen Jaubert, A. 2007: "Rural settlement”, en. J. GrahamCampbell y M. Valor, The Archaeology of Medieval Europe, pp. 76-110. Aarhus University Press, Aarhus.

Larrea, J. J. 2007: "Construir iglesias, construir territorio: las dos fases altomedievales de San Román de Tobillas (Álava)”, en J. L. Quiroga, A. M. Martínez Tejera y J. Morín de Pablos (eds.), Monasteria et territoria. Élites, edilicia y territorio en el Mediterráneo medieval (siglos V-XI), pp. 321-336. John and Erica Hedges, Oxford.

Loveluck, C. 2013: Northwestern Europe in the Early Middle Ages, c. AD 600-1150. A Comparative Archaeology. Cambridge University Press, Cambridge.

Lubritto, C., García-Collado, M. I., Ricci, P., Altieri, S., Sirignano, C. y Quirós Castillo J. A. 2017: "New Dietary Evidence on Medieval Rural Communities of the Basque Country (Spain) and its surroundings from Carbon and Nitrogen Stable Isotope Analyses: Social Insights, Diachronic Changes and Geographic Comparison", International Journal of Osteoarachaeology, doi: https://doi.org/10.1002/oa.2610.

Meiron-Jones, G. I. 1973: "The long-house: a definition”, Medieval Archaeology, 17, pp. 135-137.

Metcalf, P. 2010: The life of the longhouse: an archaeology of ethnicity. Cambridge University Press, Cambridge.

Misiego Tejeda, J. C., Marcos Contreras, G. J., Martín Carbajo, M. A., Sanz García, F. J. y Vilanueva Martín, L. A. 2005: “Guaya (Berrocalejo de Aragona, Ávila): reconstrucción de la vida y economía de un poblado en los albores de la Edad del Hierro", en A. Blanco, C. Cancelo y A. Esparza (eds.), Bronce Final y Edad del Hierro en la Península Ibérica. Encuentros de Jóvenes investigadores, pp. 207-228. Universidad de Salamanca, Salamanca.

Moore, J. D., 2012: The Prehistory of Home. University of California Press, Berkeley.

Morales Muñiz, D. C. 1992: "Pigs Husbandry in Visigoth Iberia: Fact and Theory", Archaeofauna, 1, pp. 147-155. 
Moreno Raso, I. 2014: "Longhouses del Bronce Final-Hierro I en la Península Ibérica", Arqueología y Territorio, 11, pp. 25-37.

Nissen Jaubert, A. 2003: "La maison-étable dans le nord-ouest de l'Europe. Contextes culturels, sociaux et idéologiques", Les nouvelles de l'archéologie, 92.2, pp. 28-33.

Nissen Jaubert, A. 2010: "Late Antique and early medieval high-status sites in France", Settlement and Coastal Research in the Southern North Sea Region, 33, pp. 255-273.

Peytremann, E. 2003: Archéologie de l'habitat rural dans le nord de la France du IVe au XIIe siècle. AFAM, Saint-Germain-en-Laye.

Peytremann, E. 2012: "The Archaeology of early medieval (6th-12th centuries) rural settlements in France", Arqueología de la Arquitectura, 9, pp. 213-230, doi: http://doi.org/10.3989/arqarqt.2012.11606.

Pollington, S. 2012: "The mead-hall community", Journal of Medieval History, 37.1, pp. 19-33, doi: https://doi.org/10.1016/j.jmedhist.2010.12.010.

Portass, R. 2017: The Village World of Early Medieval Northern Spain. Local Communitiy and the Land Market. The Royal Historical Society, London.

Quirós Castillo, J. A. 2011: "La arquitectura doméstica de los yacimientos rurales en torno al año 711", Zona Arqueológica, 11, 65-82.

Quirós Castillo, J. A. (dir.) 2012a: Arqueología del campesinado medieval: la aldea de Zaballa. Universidad del País Vasco, Bilbao.

Quirós Castillo, J. A. (ed.) 2012b: "Arqueología de la arquitectura y arquitectura del espacio doméstico en la alta Edad Media Europea", Arqueología de la Arquitectura, 9, pp. 131-265, doi: http://dx.doi.org/10.3989/ arqarqt.2012.11601.

Quirós Castillo, J. A. 2013a: "Los comportamientos alimentarios del campesinado medieval en el País Vasco y su entorno (siglos VIII-XIV)", Historia Agraria, 59, pp. 13-41.

Quirós Castillo, J. A. (ed.) 2013b: El poblamiento rural de época visigoda en Hispania. Arqueología del campesinado en el interior peninsular. Universidad del País Vasco, Bilbao.

Quirós Castillo, J. A. (ed.) 2016: Social complexity in Early Medieval rural communities. The North-Western Iberia Archaeological record. Archaeopress, Oxford.

Quirós Castillo, J. A. (en prensa): "Nucleation and the archaeology of rural communities in North-western Iberia".

Quirós Castillo, J. A. y Santos Salazar, I. 2012: "I villaggi medievali nell'Alto Ebro alla luce delle fonti scritte e dell'archeologia. L'emergere dei leader dei villaggi e l'articolazione dei poteri territoriali nel X secolo", en P. Galetti (a cura di), Paesaggi, comunità, villaggi medievali, Centro di Studi sull'Altomedioevo, Tomo 1, pp. 257-279. Spoleto.

Rahtz, Ph. 1976: "Buildings and rural settlement", en D. M. Wilson (ed.), The Archaeology of Anglo-Saxon England, pp. 49-98. Cambridge University Press, Cambridge.

Reynolds, A. y Quirós Castillo, J. A., 2006-2009: “Aistra Zalduondo", Arkeoikuska, 06, pp. 94-100; 07, pp. 159-167; 08, pp. 209-211; 09, pp. 176-180.

Reynolds, P. 2015: "Material culture and the economy in the age of Saint Isidore of Seville (6th and 7th centuries)", Antiquité Tardive, 23, pp. 163210, doi: https://doi.org/10.1484/j.at.5.109377.

Roig Buxó, J. 2009: "Asentamientos rurales y poblados tardoantiguos y altomedievales en Cataluña (siglos VI a X)", en J. A. Quirós Castillo (ed.), The archaeology of early medieval villages in Europe, pp. 207-251. Universidad del País Vasco, Bilbao.

Rosberg, K. 2013: "Terminology for houses and house remains", Journal of Archaeology and Ancient History, 8, pp. 3-15.

Sánchez Zufiaurre, L. 2007: Técnicas constructivas medievales: nuevos documentos arqueológicos para el estudio de la Alta Edad Media en Álava. Gobierno Vasco, Vitoria-Gasteiz.

Sanguino Vázquez, J., Oñate Baztan, P., Penedo Cobo, E. y De Torre Rodríguez, J., 2007: “'El Colegio' (Valdemoro): cambios materiales y estabilidad socioeconómica a mediados del Primer milenio a. C.”, Zona Arqueología, 10, pp. 153-174.

Santangeli Valenzani, R. 2011: Edilizia residenziale in Italia nell'altomedioevo. Carocci, Roma.

Santos Salazar, I. y Quirós Castillo, J. A. (en prensa): "Le basi economiche del potere pubblico in una periferia molto dinamica: Castiglia, Álava,
Pamplona (900-1050)", en V. Loré, Beni pubblici, beni del re. Le basi economiche dei poteri regi nell'alto Medioevo. Brepols.

Schreg, R. 2012: "Farmsteads in early medieval Germany - architecture and organisation", Arqueología de la Arquitectura, 9, pp. 247-265, doi: https:// doi.org/10.3989/arqarqt.2012.11608.

Steadman, S. R. 2015: Archaeology of Domestic Architecture and the Human use of the Space. Left Coast Press, Oxon.

Sykes, N. 2014: Beastly questions: animal answers to archaeological issues. Bloomsbury, London.

Taylor, C., 1977: "Polyfocal Settlement and the English Village", Medieval Archaeology, 21, pp. 189-193.

Tejerizo, C. 2012: "Early Medieval household archaeology in Northwest Iberia (6th-11th centuries)", Arqueología de la Arquitectura, 9, pp. 181-184, doi: https://doi.org/10.3989/arqarqt.2012.11604.

Tejerizo, C. 2013: "La arquitectura doméstica en las aldeas meseteñas altomedievales", en J. A. Quirós Castillo (ed.), El poblamiento rural de época visigoda en Hispania. Arqueología del campesinado en el interior peninsular, pp. 289-328. Universidad del País Vasco, Bilbao.

Tejerizo, C. 2015: "Estructuras de fondo rehundido alto medievales en la Península Ibérica", Munibe 65, pp. 215-237.

Tejerizo, C. 2017: Arqueología de las sociedades campesinas en la cuenca del Duero durante la primera Alta Edad Media. Universidad del País Vasco, Bilbao.

Terry, R. E., Fernandez, F. G., Parnell, J. J. e Inomata, T. 2004: "The story in the floors: chemical signatures of ancient and modern Maya activities at Aguateca, Guatemala", Journal of Archaeological Science, 31, pp. 12371250, doi: https://doi.org/10.1016/s0305-4403(04)00066-4.

Thomas, G. 2012: "The Prehistory of Medieval Farms and Villages: from Saxons to Scandinavians", en N. Christie y P. Stamper (eds.), Medieval Rural Settlement. Britain and Ireland, AD 800-1600, pp. 43-62. Oxford: Windgather Press.

Ulmschneider, K. 2010: "Settlement hierarchy", en H. Hamerow, S. Crawford y D. Hinton (eds.), A Handbook of Anglo-Saxon Archaeology, pp. 156-171. Oxford: Oxford University Press.

Unanua González, R. y Erce Domínguez, A. 2014: “Aportes al conocimiento de los yacimientos al aire libre, nuevos campos de hoyos en Navarra", Cuadernos de Arqueología de la Universidad de Navarra, 22, pp. 73-118.

Urbina, D., Morín, J., Ruiz, L. A., Agustí, E. y Montero, I. 2007: “El yacimiento de Las Camas, Villaverde, Madrid. Longhouses y elementos orientalizantes al inicio de la Edad del Hierro, en el valle medio del Tajo", Gerión, 25.1, pp. 45-82.

Urbina, D. y Urquijo, C. 2012: "El yacimiento de Las Lunas, Yuncler (Toledo): una ciudad de cabañas", en J. Morín de Pablos y D. Urbina Martínez (eds.), El Primer Milenio A C en la Meseta Central. De la longhouse al oppidum, vol. 1, pp. 173-194. Audema, Madrid.

Vaccaro, E. 2005: "La città di Cosa-Ansedonia tr ala romanizzazione e il basso medioevo: una discussione su 'Cosa V'", Archeologia Medievale, 32, pp. 484-494.

Valenti, M. 2004: L'insediamento altomedievale nelle campagne toscane. All'Insegna del Giglio, Firenze.

Vázquez Liz, P., Prieto-Martínez, M.-P. y Núñez Jato, J. F. 2015: “El pasado olvidado: El sitio del II y I milenio BC de Pena Fita (Adai, Lugo) en el contexto de las 'longhouses' del NW Peninsular”, Gallaecia, 34, pp. 9-56.

Veiga de Oliveira, E., Galhano, F. y Pereira B. 1994: Construções Primitivas em Portugal. Lisboa.

Vigil-Escalera Guirado, A. 2000: "Cabañas de época visigoda: evidencias arqueológicas del sur de Madrid. Tipología, elementos de datación y discusión", Archivo Español de Arqueología, 73, pp. 223-252, doi: https://doi. org/10.3989/aespa.2000.v73.325.

Vigil-Escalera Guirado, A. 2007: "Granjas y aldeas altomedievales al Norte de Toledo (450-800 d. C.)", Archivo Español de Arqueología, 80, pp. 239284, doi: https://doi.org/10.3989/aespa.2007.v80.35.

Vigil-Escalera Guirado, A. 2015: "El espacio doméstico en el ámbito rural del centro de la península ibérica entre los siglos V y IX d. C.", en M. E. Díez Jorge y J. Navarro Palazón (eds.), La casa medieval en la Península Ibérica, pp. 519-539. Sílex, Madrid. 
Villanueva Martín, L., Carmona Ballestero, E., Arnaiz Alonso, M. A. y Delgado Arceo, M. E. 2014: "La articulación del espacio en el "campo de hoyos' de Manantial de Peñuelas (Celada del Camino, Burgos)”, en M. A. Brezmes Escribano, A. Tejeiro Pizarro y O. Rodríguez Monterrubio (coords.), Arqueología en el Valle del Duero. Del Neolitico a la Antigüedad tardia: nuevas perspectivas, pp. 109-127. Glyphos, Valladolid.

Volmer, L., Zimmermann, W. H. (eds.) 2012: Glossary of Prehistoric and Historic Timber Buildings / Glossar zum prähistorischen und historischen Holzbau. Rahden/Westf, Leidorf.

Wickham, C. 2005: Framing the Early Middle Ages. Europe and the Mediterranean, 400-800. Oxford University Press, Oxford.
Wickham, C. 2011: "The Changing Composition of early élites", en F. Bougard, H.-W- Goetz y R. Le Jan (eds.), Théorie et pratiques des élites au Haut Moyen Âge. Conception, perception et réalisation sociale, pp. 5-18. Brepols, Turnhout.

Wintherhalder, B., Puleston, C. y Ross, C. 2015: "Production risk, interannual food storage by household and population-level consequences in seasonal prehistoric agrarian societies", Environmental Archaeology 20.4, pp. 337-348, doi: https://doi.org/10.1179/1749631415y.0000000025.

Zimmermann, W. H. 1998: "La cartographie de phosphates au service de l'archéologie de l'habitat", en M. Dabas, H. Delétang, A. Ferdière, C. Jung y W. Haio Zimmermann, La prospection, pp. 207-216. Paris, Errance. 